\title{
Optimal feeder reconfiguration in distributed generation environment under time-varying loading condition
}

\author{
Yanrenthung Odyuo ${ }^{1} \cdot$ Dipu Sarkar $^{1} \cdot$ Lilika Sumi $^{1}$
}

Received: 30 July 2020 / Accepted: 7 April 2021

Published online: 01 May 2021

(c) The Author(s) 2021

OPEN

\begin{abstract}
The development and planning of optimal network reconfiguration strategies for electrical networks is greatly improved with proper application of graph theory techniques. This paper investigates the application of Kruskal's maximal spanning tree algorithm in finding the optimal radial networks for different loading scenarios from an interconnected meshed electrical network integrated with distributed generation (DG). The work is done with an objective to assess the prowess of Kruskal's algorithm to compute, obtain or derive an optimal radial network (optimal maximal spanning tree) that gives improved voltage stability and highest loss minimization from among all the possible radial networks obtainable from the DG-integrated mesh network for different time-varying loading scenarios. The proposed technique has been demonstrated on a multiple test systems considering time-varying load levels to investigate the performance and effectiveness of the suggested method. For interconnected electrical networks with the presence of distributed generation, it was found that application of Kruskal's algorithm quickly computes optimal radial configurations that gives the least amount of power losses and better voltage stability even under varying load conditions.
\end{abstract}

\section{Article Highlights}

- Investigated network reconfiguration strategies for electrical networks with the presence of Distributed Generation for time-varying loading conditions.

- Investigated the application of graph theory techniques in electrical networks for developing and planning reconfiguration strategies.

- Applied Kruskal's maximal spanning tree algorithm to obtain the optimal radial electrical networks for different loading scenarios from DG-integrated meshed electrical network.

Keywords Network reconfiguration · Distributed generation · Graph theory · Kruskal's maximal spanning tree algorithm

\section{Introduction}

In the delivery and supply of electricity, the distribution stage is the final stage following the generation and transmission stages. The electrical distribution network delivers the electrical power to the consumers via its distribution feeders. Certain problems faced in lengthy distribution feeders include fall in voltage levels [1], power factor distortion, power loss, etc. In order to mitigate these problems, the authors in [2-4] implemented measures such as embodiment of additional hardware like tap-changing transformers, shunt capacitors, FACTs devices etc. Apart

Dipu Sarkar, dipusarkar5@rediffmail.com; Yanrenthung Odyuo, yanrenthungodyuo@yahoo.com; Lilika Sumi, lilikasumi18@gmail.com | ${ }^{1}$ Department of Electrical and Electronics Engineering, National Institute of Technology, Dimapur, Nagaland 797103, India. 
from these approaches, another important approach is by reconfiguring the network via network reconfiguration by operating the series and sectional switches [5, 6]. By means of network reconfiguration, the power lines can be restructured in such a way that an optimal radial network may be obtained thereby providing a path for optimal power to flow in the network. The authors in $[7,8]$ discussed that appropriate reconfiguration arrangement can contribute towards reduction in power loss in the network. In [9] the authors have used reconfiguration studies for microgrid applications, and in [10] the authors have worked on developing reconfiguration strategies for shipboard power systems considering local and global reconfiguration. The advantage of network reconfiguration technique over other methods is that just by operating the sectional and tie line switches network reconfiguration can help obtain an optimal stable network with minimized losses, with no requirement for additional equipment or supports. In [11], the authors found that application of graph theory techniques such as Edmond's Maximal Spanning Tree Algorithm can help obtain optimal radial network configurations from an originally meshed network. It may be worth noted that in practice, radial structured networks are generally used in rural and sub-urban areas due to several advantages it offers such as lower short circuit current and less complex relay coordination. Also, sometimes during situations such as during fault or planned maintenance condition, a mesh network may be required to be reconfigured into a radial network thereby keeping the supply uninterrupted when the maintenance is being carried out. Some of the advantages of network reconfiguration were further discussed by the authors in [12] such as trimming of peak demands leading to curtailment of overburdening of network components and enhancing the system stability.

A substantial amount of time has been invested by contemporary researchers in studying the influence of network reconfiguration in achieving loss reduction [13] and voltage stability improvement [14]. It can be seen from the works presented in [15-18] that most of the strategies are focused on reducing the feeder active power losses and enhancement of voltage stability for constant loading condition. This particular aspect of considering only constant loading condition becomes a limitation since in a practical scenario the power demands in a distribution network varies with time. The demand for electricity depends on the consumers, and the requirements of power by the consumers vary throughout the day; thus in actual practice, the demand seldom remains constant instead it varies continuously with time. This varying loading scenario follows a pattern, and thus by relying on past historical data, a predictive varying load model can be generated in the form of daily load curves.
By using the information from the daily load curves, network reconfiguration plans can be formulated for the different varying load scenarios. The authors in $[12,19]$ considered time-varying load demand in the study and by employing network reconfiguration techniques were able to obtain the best network with minimum system power loss and higher voltage stability.

Now, the demand for electricity is always on the rise, but the same cannot be said for the improvement in the transmission infrastructure. Thus, with increasing demand, the power transmission and distribution lines operate under a heavy burden and sometimes even under over loaded conditions, resulting in high transmission losses and low voltage stability. One ingenious solution to this problem is to connect certain capacity power plants or distributed generation (DG) sources directly or nearby to the load centres, thereby minimizing the burden on the transmission and distribution networks, which ultimately contributes to reduction in transmission losses and improvement in the voltage stability [20].

Apart from the potential benefits that come with the integration of distributed generation (DG) to an electrical network, another aspect of DG integration is its impact on the topology of the power system. In a traditional power system architecture or a centralized power system topology, the distribution or transfer of power is unidirectional [21] i.e., electricity is transferred from the centralized generating stations to the loads through the transmission and distribution lines, but in a power system network where small-scale DGs are connected directly to the distribution side any excess power generated by the DG can be fed back to the main grid via the feeders thereby making the flow of power in the feeder bidirectional [22]. This simple characteristic of an electrical network with and without DGs contributes to huge changes in the planning and implementation of network reconfiguration strategies of respective power system networks. Proper integration of DG offers technical benefits including power loss minimization and improvement in voltage stability, and also environmental as well as economic benefits [23-25]. The incorporation of DGs to supply the demand during peak load periods renders benefits in both technical as well as economical areas. DGs can also supply reactive power for improving the voltage profile to meet real power demands [26]. The technical benefits of incorporating distributed generation include voltage stability improvement, power loss minimization, distribution capacity release, improved system reliability and voltage support $[27,28]$. The integration of renewable energy-based DGs also has a small likelihood of causing some disturbance in the system stability owing to its intermittent nature which is affected by natural conditions, which ultimately will have some impact on the electrical energy losses in distribution lines, voltage 
profile, Var Control and set of pollutants produced by the grid, etc. [29-31].

Now, with the presence of distributed generation in the grid, the issue of distribution feeder planning and reconfiguration becomes more complex. As discussed earlier, due to the bidirectional nature of power flow in electrical networks with DG, the reconfiguration process and strategies for an electrical network with and without DG become slightly different. It can be observed from the literature that by means of network reconfiguration an optimal radial reconfigured network with minimized line losses and improved voltage stability can be obtained. However, there still exists some issues (with regards to computation) when carrying out network reconfiguration techniques. The larger the system, the more complex it becomes to find the optimal radial configuration via manual network reconfiguration process, since if a network has ' $n$ ' number of switches, then there exists ' $2^{\text {n' }}$ possible switching combinations with some set of switching configurations resulting in radial network topologies. Thus, for large systems, any manual attempts to find the optimal radial network by tracking all the possible configurations becomes a tedious task involving an impractically long duration of time. The proper application of graph theory techniques in the field of network reconfiguration has been found helpful in resolving these issues.

In this paper, the application of graph theory-based Kruskal's maximal spanning algorithm in electrical networks for developing reconfiguration and planning strategies is further investigated for a network with time-varying load model and in the presence of DG. The work is done with an objective to assess the ability of Kruskal's maximal spanning algorithm to compute an optimal radial network (an optimal maximum spanning tree) that gives the best voltage stability and highest loss minimization from among all the possible radial configurations that can be obtained from the original DG-integrated connected mesh network for different time-varying loading scenarios. A computation is carried out on a modified IEEE 30 bus network in MATLAB to assess the performance of the suggested method.

\section{Theory}

\subsection{Reconfiguration strategy}

Consider a 4-node power distribution network consisting of one power supply bus, three load buses, and four feeders, as shown in Fig. 1. Let the reactance (in p.u.) of the feeders be $X_{1}, X_{2}, X_{3}$ and $X_{4}$, respectively, and the voltage (in p.u.) of the nodes be $V_{1} \angle \delta_{1}, V_{2} \angle \delta_{2}, V_{3} \angle \delta_{3}$, and $V_{4} \angle \delta_{4}$

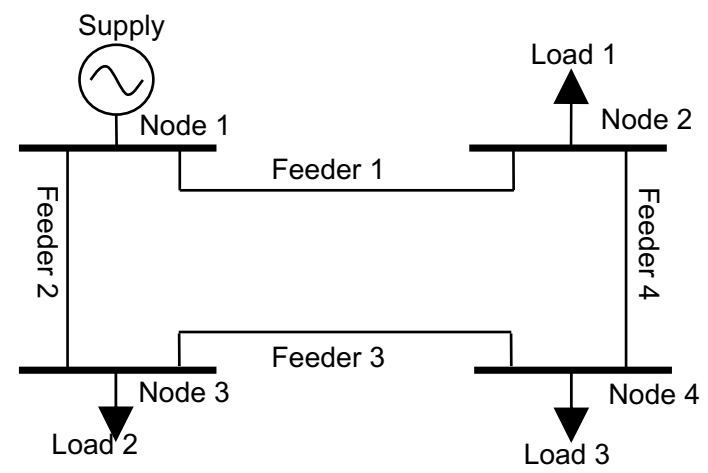

Fig. 1 A 4-node mesh network

respectively. From the available data, the load-carrying capabilities of the feeders 1 to 4 can be calculated as,

$P_{1}=\left|\left(v_{1} v_{2} / X_{1}\right) \sin \left(\delta_{1}-\delta_{2}\right)\right|$

$P_{2}=\left|\left(v_{1} v_{3} / X_{2}\right) \sin \left(\delta_{1}-\delta_{3}\right)\right|$

$P_{3}=\left|\left(v_{3} v_{4} / x_{3}\right) \sin \left(\delta_{3}-\delta_{4}\right)\right|$

$P_{4}=\left|\left(v_{2} v_{4} / X_{4}\right) \sin \left(\delta_{2}-\delta_{4}\right)\right|$

Now, if we consider that the load carrying capabilities of the feeders are in the order $P_{1}>P_{2}>P_{3}>P_{4}$, then reconfiguring the network by eliminating the feeder with least load-carrying capability (i.e. feeder 4), a radial network can be obtained from the originally mesh network. The feeder can be eliminated or disconnected by opening the sectionalizing switch as shown in Fig. 2. The newly obtained radial network consists of only the feeders with high load carrying capability.

The cost matrix (weight matrix) can also be obtained from the load-carrying capability of feeders. For a system with $\mathrm{n}$ number of nodes, the size of the cost matrix (weight matrix) will be $n \times n$. If ' $c$ ' represents the cost matrix, then its elements will be represented as $c_{i j}$, where $c_{i j}$ represents the load-carrying capability (in p.u.) of the feeder connected between node i and node j. For the system shown in Fig. 1 , the cost matrix will be a $4 \times 4$ matrix. The elements of the cost matrix can be calculated as, $c_{11}=c_{22}=c_{33}=c_{44}=c_{14}=c_{41}=c_{23}=c_{32}=0$, since these are either single nodes or there are no direct connection between these nodes. As for the connected nodes, 


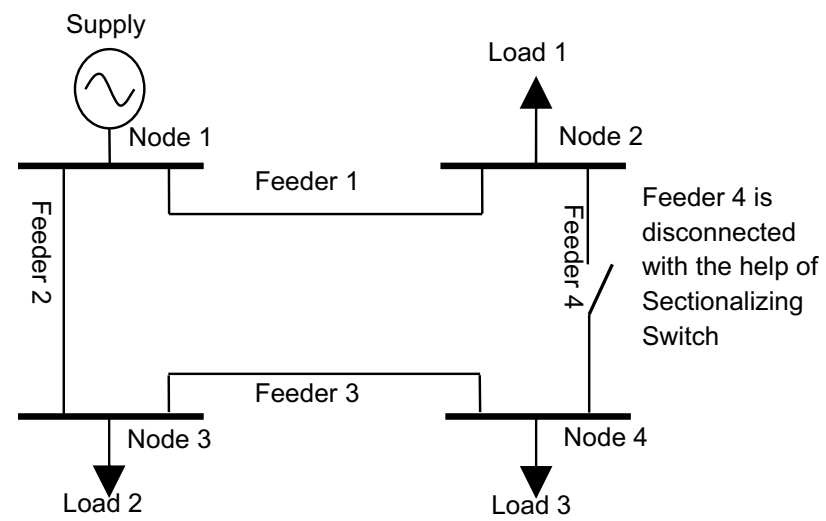

Fig. 2 A 4-node reconfigured radial network

the nonzero cost matrix elements are, $c_{12}=c_{21}=P_{1}$, $c_{13}=c_{31}=P_{2}, c_{34}=c_{43}=P_{3}$, and $c_{24}=c_{42}=P_{4}$. The values of the cost matrix elements can be calculated using the Newton-Raphson load flow analysis. For the reconfigured radial network shown in Fig. 2 , since feeder 4 is now disconnected with help from sectionalizing switch, node 4 will receive the supply from feeder 3 only, and the new cost matrix element for $c_{24}=c_{42}=P_{4}=0$.

In Kruskal's algorithm, a radial network is extracted from a mesh network by disconnecting the feeder with lowest load-carrying capability from among all the feeders in a step-by-step manner. This results in a radial network where all the nodes are connected only by the feeders with higher load-carrying capacity. It is observed that for the reconfigured radial network obtained through Kruskal's algorithm, the active and reactive power losses in each feeder are also minimized. By minimizing the overall power loss of the system, the voltage stability of the system is also further improved.

For a 4-node network, the number of possible network configurations would be $2 \wedge 4$. For a mesh network with ' $n$ ' number of feeders, there will be $2 \wedge n$ possible switch configurations. The number of possible feeder configurations increases with the increase in the number of feeders in the network, which also makes the process of finding an optimal radial network from an originally mesh network more complex. In large networks, trying to find an optimal radial network by testing every possible network configuration is a very tedious, time consuming and labor intensive process, and if a time-varying loading condition is considered, the task becomes even more difficult. In such circumstances, the Kruskal's algorithm helps to obtain an optimal radial network in less time and makes the process easier.

Certain important criteria should be maintained during the reconfiguration process, three such important criteria are:

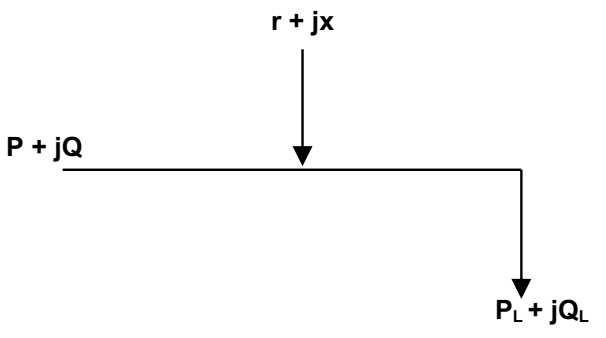

Fig. 3 Single line system

i. All nodes should be in service.

ii. The maximum power transfer capability of a feeder should not be violated during each operation.

iii. The sectionalizing switches of the feeders with lower load-carrying capability should be opened first compared to the other lines.

The final radial network obtained using Kruskal's maximal spanning tree normally contains the feeders with higher load-carrying capability, while the feeders with lower loadcarrying capability are disconnected.

\subsection{Voltage stability indicator (L-index) evaluation}

For the voltage stability analysis, single feeder equivalent method of distribution network which comprises of multiple feeders [32] has been employed. The single line system is shown in Fig. 3. $P=$ injected real power, $Q=$ injected reactive power, $R=$ line resistance, $X=$ line reactance, $P_{\mathrm{L}}=$ real load, $Q_{\mathrm{L}}=$ reactive load, $V=$ voltage.

The real power equations from Fig. 3 may be derived as

$P=r\left(P^{2}+Q^{2}\right) / V^{2}+P_{\mathrm{L}}$

or, $P-P_{L} / r=\left(P^{2}+Q^{2}\right) / V^{2}$

and the reactive power equations from Fig. 3 may be derived as

$Q=x\left(P^{2}+Q^{2}\right) / V^{2}+Q_{L}$

or, $Q-Q_{\mathbf{L}} / \boldsymbol{x}=\left(\boldsymbol{P}^{2}+\boldsymbol{Q}^{2}\right) / \boldsymbol{V}^{2}$

From (6) and (8), the terms $\left(P^{2}+Q^{2}\right) / V^{2}$ can be eliminated, and by rearranging the equations we acquire

$x\left(P-P_{L}\right)=r\left(Q-Q_{L}\right)$

Considering sending end voltage as reference voltage (thus, $V=1$ ), and on rearranging Eq. (9), and eliminating $Q$ from Eq. (5), a quadratic equation in terms of $P$ is acquired. 


$$
\begin{aligned}
& \left(r^{2}+x^{2}\right) P^{2}-\left(2 x^{2} P_{L}-2 r x Q_{L}+r\right) P \\
& \quad+\left(x^{2} P_{L}^{2}+r^{2} Q_{L}^{2}-2 r x P_{L} Q_{L}+r P_{L}\right)=0
\end{aligned}
$$

From Eq. (10) the real power $P$ can be derived as, or, $r=P_{\text {loss }} /\left[\left(P_{L}+P_{\text {loss }}\right)^{2}+\left(Q_{L}+Q_{\text {loss }}\right)^{2}\right]$

$P=\frac{2 x^{2} P_{\mathrm{L}}-2 r x Q_{\mathrm{L}}+r}{2\left(r^{2}+x^{2}\right)} \pm \frac{\left[\left(2 x^{2} P_{\mathrm{L}}-2 r x Q_{\mathrm{L}}+r^{2}\right)-4\left(r^{2}+x^{2}\right) *\left(x^{2} P_{\mathrm{L}}^{2}+r^{2} Q_{\mathrm{L}}^{2}-2 r x P_{\mathrm{L}} Q_{\mathrm{L}}+r P_{\mathrm{L}}\right)\right]^{1 / 2}}{2\left(r^{2}+x^{2}\right)}$

||lly, taking into consideration the symmetry between the

$$
x=Q_{\text {loss }} /\left[\left(P_{L}+P_{\text {loss }}\right)^{2}+\left(Q_{L}+Q_{\text {loss }}\right)^{2}\right]
$$
real power and the reactive power in power systems, the reactive power $Q$ can be derived as,

Now, for reduced network,

$Q=\frac{2 x^{2} Q_{L}-2 r x P_{L}+x}{2\left(r^{2}+x^{2}\right)} \pm \frac{\left[\left(2 x^{2} P_{L}-2 r x Q_{L}+r^{2}\right)-4\left(r^{2}+x^{2}\right) *\left(x^{2} P_{L}^{2}+r^{2} Q_{L}^{2}-2 r x P_{L} Q_{L}+r P_{L}\right)\right]^{1 / 2}}{2\left(r^{2}+x^{2}\right)}$

Now, for $P$ and $Q$ of Eqs. (11) and (12) to have real roots, the determinant of the quadratic equations should be $b^{2}-4 a c>0$.

Hence,
$L_{\text {index }}=4\left[\left(x_{\text {eq }} P_{\text {Leq }}-r_{\text {eq }} Q_{\text {Leq }}\right)^{2}+x_{\text {eq }} Q_{\text {Leq }}+r_{\text {eq }} P_{\text {Leq }}\right]$

Where $L_{\text {index }}=$ voltage stability index,$r_{\text {eq }}=$ equivalent resistance for single line, $x_{\text {eq }}=$ equivalent reactance for single

$\left(2 x^{2} P_{L}-2 r x Q_{L}+r\right)^{2}-4\left(r^{2}+x^{2}\right)\left(x^{2} P_{L}^{2}+r^{2} Q_{L}^{2}-2 r x P_{L} Q_{L}+r P_{L}\right)>0$

or, $\left[\left(2 x^{2} P_{L}-2 r x Q_{L}+r\right) *\left(2 x^{2} P_{L}-2 r x Q_{L}+r\right)\right]$

$-4\left[r^{2}\left(x^{2} P_{L}^{2}+r^{2} Q_{L}^{2}-2 r x P_{L} Q_{L}+r P_{L}\right)+x^{2}\left(x^{2} P_{L}^{2}+r^{2} Q_{L}^{2}-2 r x P_{L} Q_{L}+r P_{L}\right)\right]>0$

Which on simplification, reduces to,

$\left(4\left[\left(x P_{\mathrm{L}}-r Q_{\mathrm{L}}\right)^{2}+x Q_{\mathrm{L}}+r P_{\mathrm{L}}\right]<1\right)$

Based on the network loading, if the calculated value of the LHS of Eq. (15) goes beyond the critical limit i.e., 1, then the power becomes imaginary and it results in voltage collapse. The LHS of Eq. (15) is also termed as the voltage stability index and is represented by the term $L_{\text {index }}$.

Thus for a stable system, $L_{\text {index }}<1$.

Now, considering Eq. (5) with sending ending voltage as reference voltage (thus, $V=1$ ), the equation becomes

$P=r\left(P^{2}+Q^{2}\right)+P_{L}$

or, $P-P_{\mathrm{L}}=r\left(P^{2}+Q^{2}\right)$

But we know that, Generation $(P)$-Demand $\left(P_{\mathrm{L}}\right)=$ Losses $\left(P_{\text {loss }}\right)$.

Thus Eq. (17) becomes,

$P_{\text {loss }}=r\left(P^{2}+Q^{2}\right)$ line, $P_{\text {Leq }}=$ total real loads in the distribution network, $Q_{\text {Leq }}=$ total reactive loads in the distribution network.

And from Eqs. (19) and (20), we get,

$r_{\text {eq }}=\left(\sum P_{\text {loss }}\right) /\left[\left(P_{\text {Leq }}+\sum P_{\text {loss }}\right)^{2}+\left(Q_{\text {Leq }}+\sum Q_{\text {loss }}\right)^{2}\right]$

$x_{\text {eq }}=\left(\sum Q_{\text {loss }}\right) /\left[\left(P_{\text {Leq }}+\sum P_{\text {loss }}\right)^{2}+\left(Q_{\text {Leq }}+\sum Q_{\text {loss }}\right)^{2}\right]$

where $P_{\text {loss }}$ and $Q_{\text {loss }}$ are the active and reactive power losses of the system.

The voltage stability index i.e. $L_{\text {index }}$ value varies between 0 and 1 , with values nearer to 0 designating a more stable system. 


\subsection{Kruskal's maximal spanning tree and its application in the present study}

A graph is a set of nodes connected with edges. And, a connected graph whose edges have weights assigned to it forms a network. Figure 4(a) shows an arbitrary network $G$ with three nodes $A, B$ and $C$ and three edges $A B, A C$ and $B C$ with weights 1,2 and 3 , respectively.

A connected sub-graph extracted from the graph $\mathrm{G}$, which contains no cycles or loops in it, forms a spanning tree $(T)$ of G. Figure 4(b), (c) and (d) is possible spanning tree of Fig. 4(a). The spanning tree with the most weight forms the maximum weight spanning tree. Kruskal's algorithm [33] helps compute a maximal spanning tree from a given network by initially sorting the edges in order of decreasing weight then systematically constructing a maximal spanning tree by prioritizing the edges with more weights in each step of forming the spanning tree.

\subsubsection{Kruskal's maximal spanning tree algorithm}

Consider, a graph G represented by,

$G=\left\{\left((u, v), e_{u, v}\right): u, v\right.$ are nodes, $e_{u, v} \rightarrow$ weight of the edge $\left.(u, v)\right\}$

Then, the target spanning tree $T$ may be represented as, $T=\left\{\left((u, v), e_{u, v}\right): u, v\right.$ are nodes, $e_{u, v}$ is the weight of the edge $(u, v)$

And edge, $E=\left\{(u, v), e_{u, v}\right\}$.

To obtain a maximum spanning tree from a given network $G$, a simplified procedure based on Kruskal's [34-36] may be summarized as:

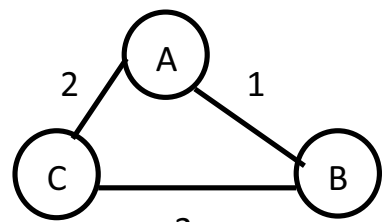

$3(a)$

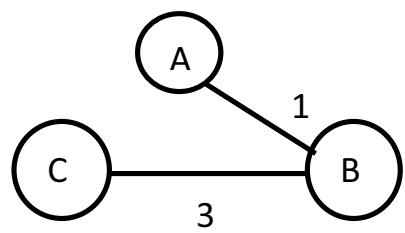

(c)
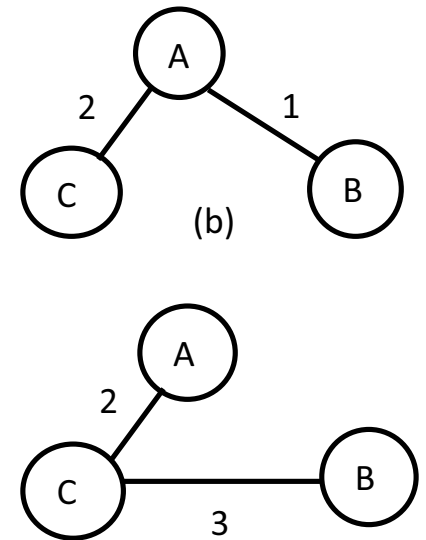

(d) i. Arrange the edges of $\mathrm{G}$ in decreasing order of weight via sorting. And let $T$ be the set of edges constituting the maximum spanning tree. Initially, $T=\Phi$.

ii. Add the first edge to $T$.

iii. Continue adding the remaining edges to $T$ one edge at a time always checking that it does not form a loop in $T$. Exit and report $\mathrm{G}$ to be disconnected when no further edges can be added.

iv. If the obtained tree $(T)$ has $n-1$ edges ( $n=$ number of nodes in $G$ ) stop and output $T$. Otherwise go to step 3.

The flow chart of the Kruskal's Maximal Spanning Tree Algorithm has been shown in Fig. 5 .

\section{Results and discussions}

Here, for different varying loading scenarios, Kruskal's maximal spanning tree algorithm was applied to find an optimal radial network (optimal spanning tree) from among the many possible spanning trees present in a meshed electrical network integrated with distributed generation. The proposed algorithm was tested on a modified IEEE 30 node test system integrated with distributed generation, with each feeder of the test system containing series sectionalizing switches numbered from $\mathrm{S} 1$ to $\mathrm{S} 41$. All simulations were carried out in MATLAB and MATLAB-based Power System Analysis Toolbox (PSAT). A representation of the 30 -node test system is shown in Fig. 6 , and the test system input data for feeder and load have been shown in Appendix Tables 12 and 13 , respectively, and are also obtainable from [37]. The DG unit is modelled as a wind turbine with doubly fed induction generator (DFIG) as per [38] and its output is considered to be constant. The parameters of the DG are also given in Appendix Table 15. Initially, a load flow analysis was carried out on the original mesh network, and from the information obtained, the node with the least voltage magnitude value (in per unit value) was chosen as the location for DG installation. In the case of 30-node test system, the bus (node) with the least value of voltage magnitude was found to be bus 30 . The DG was thus installed at the chosen node under the constraint that the capacity of the installed DG does not exceed the base load of that particular node. Thus, for the modified 30 node system case since the base load at bus 30 is $10.6 \mathrm{MW}$, the capacity of the DG is thus fixed at a constant output of $10.6 \mathrm{MW}$ for all cases. Similar procedure was done for the cases for 3-node test system [37] and a 14-node test system [39].

Fig. 4 A Network and its Spanning Trees 
Fig. 5 Flowchart of Kruskal's maximal spanning tree algorithm

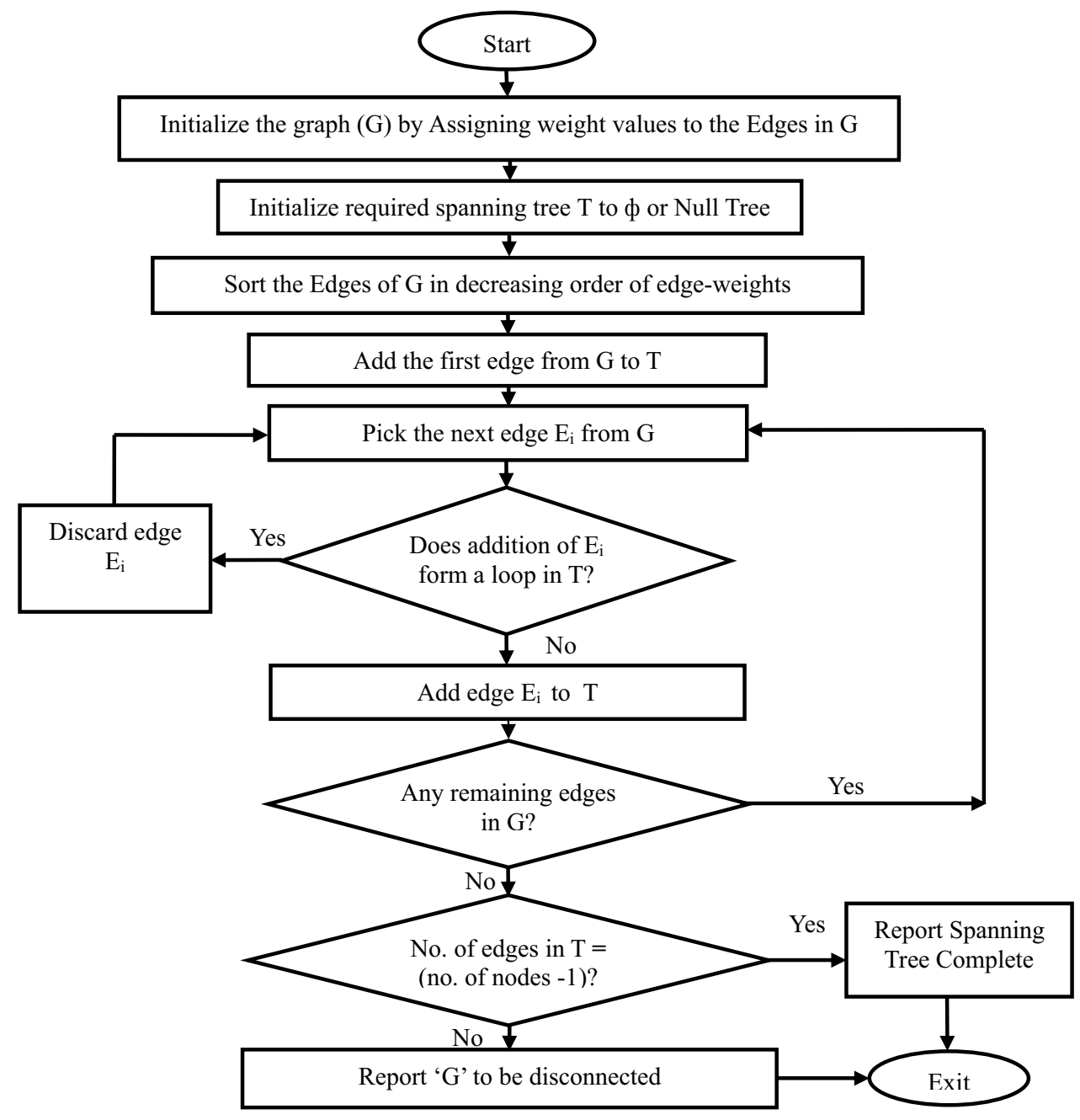

Consumers play an important part in shaping the load demand in electrical distribution systems. Depending on several factors the demand for power may rise or fall at any given time. By collecting and accumulating information over a period of time on power consumption in an area, the load demand in that area can be predicted following the pattern of consumption. One of the most popular method of observing and planning for the variable loading condition is through the information obtained via daily load curves. Since the load demands in a distribution system vary with time, it is reasonable to predict that in accordance with the time-varying load demands the optimal radial network which yields the optimal voltage stability will also vary. Thus, there potentially exists different optimal radial configurations corresponding to the different loading scenarios. Therefore, formulating network reconfiguration strategies and plans considering different varying loading scenarios can help power system operators better understand and well equipped to handle network reconfiguration tasks whenever required to do so.
In this study, we have considered a time-varying model based on data as given in Appendix Table 14. Figure 9 characterizes a typical daily load curve (with values in p.u.) for a 24-h time interval based on the time-varying demand furnished in appendix Table 14. By applying Kruskal's Maximal Spanning Tree algorithm, we have tried to obtain an optimally reconfigured radial network which yields lower losses and better voltage stability index value corresponding to the different loading conditions.

Initially we have considered a small network and carried out a detailed computation on a 3-node test system taken from Example 6.7 of [35], including a comparison study between all manually obtainable possible radial configurations and the radial configuration obtained via application of the Kruskal's algorithm, followed by Kruskal's computation of optimal radial networks for varying load scenario. The results of the computation carried out have been presented in Tables 1 and 2, respectively. It may be seen from Table 1 that the radial network computed by the Kruskal's algorithm corresponds to the best possible radial network obtained via manual operation of the switches. 
Fig. 6 Modified IEEE 30-node test system considered for the study

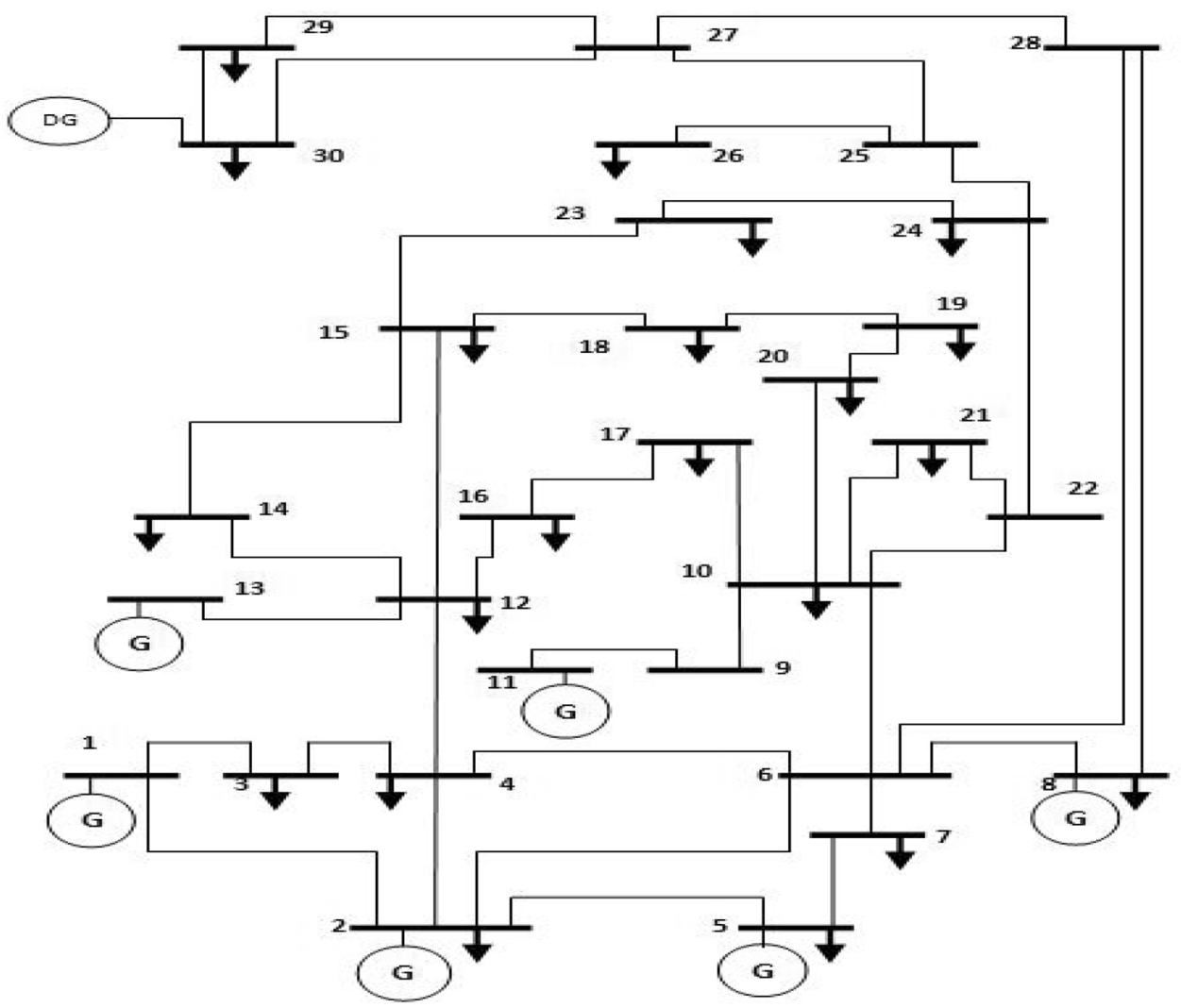

Table 1 Comparison of the radial networks obtained via manual switching and via application of Kruskal algorithm for a 3-node test system with and without DG integration

\begin{tabular}{|c|c|c|c|c|c|c|}
\hline DG status* & Configuration No. & $\begin{array}{l}\text { Switches that should be opened in } \\
\text { order to obtain a radial configura- } \\
\text { tion }\end{array}$ & P-loss (MW) & Q-loss (MVAr) & L-index (p.u.) & Time taken (seconds) \\
\hline \multirow[t]{4}{*}{0} & Manual switching 1 & S3 & 19.4744 & 40.9814 & 0.2829 & Not applicable \\
\hline & Manual switching 2 & S2 & 52.39644 & 104.7929 & 0.6137 & -do- \\
\hline & Manual switching 3 & S1 & 35.16448 & 92.712 & 0.5226 & -do- \\
\hline & Kruskal's configuration & S3 & 19.4744 & 40.9814 & 0.2829 & 1.253 \\
\hline \multirow[t]{4}{*}{1} & Manual switching 1 & S3 & 6.595451 & 39.64932 & 0.1974 & Not applicable \\
\hline & Manual switching 2 & S2 & 19.91884 & 68.27353 & 0.3786 & -do- \\
\hline & Manual switching 3 & S1 & 10.01335 & 55.2271 & 0.2783 & -do- \\
\hline & Kruskal's configuration & S3 & 6.595451 & 39.64932 & 0.1974 & 1.241 \\
\hline
\end{tabular}

*Where, 0 = network without DG, and 1 = network with DG

Similarly, computation was also carried out for the modified 30-node test system. For the 30-node test system, at base loading condition, the proposed technique recommends that sectionalizing switches $\mathrm{S} 3, \mathrm{~S} 6, \mathrm{~S} 8, \mathrm{~S} 12, \mathrm{~S} 20, \mathrm{~S} 23, \mathrm{~S} 2$ $6, S 28, S 31, S 32, S 38, S 40$ should be open to successfully reconfigure the original network into the optimal radial network. When load flow calculation was done on the resulting radial network, we obtained a total active and reactive power losses of $25.0578 \mathrm{MW}$ and 74.4049 MVAr, respectively, and a voltage stability index value of 0.5516 . Unlike a small network where all its radial networks can be manually mapped, for large networks it is complex and lengthy to obtain all possible radial networks via manual operation. Thus, to validate the optimality of the radial network obtained via the proposed algorithm at base loading condition, its performance is compared with that of the performance of ten manually configured radial reconfigured networks (also at base loading condition). The ten manually reconfigured radial networks as the name implies are radial networks obtained by manually operating the switches without relying on graph theory techniques, and are just a small number of the many potential radial networks that can be obtained 
Table 2 Performance of the radial networks obtained via application of Kruskal algorithm for a 3-node test system with and without DG integration for varying loading

\begin{tabular}{|c|c|c|c|c|c|c|c|}
\hline Algorithm used & Loading (p.u.) & DG status* & $\begin{array}{l}\text { Recommended switches be opened in } \\
\text { order to obtain a radial configuration }\end{array}$ & Ploss (MW) & Qloss (Mvar) & L-index & Time(s) \\
\hline \multirow[t]{12}{*}{ Kruskal's } & \multirow[t]{2}{*}{1} & 0 & S3 & 19.4744 & 40.9814 & 0.2829 & 1.253 \\
\hline & & 1 & S3 & 6.595451 & 39.6493 & 0.1974 & 1.241 \\
\hline & \multirow[t]{2}{*}{0.9} & 0 & S3 & 15.41466 & 32.46648 & 0.2521 & 1.120 \\
\hline & & 1 & S3 & 5.029018 & 35.77598 & 0.1911 & 1.308 \\
\hline & \multirow[t]{2}{*}{0.8} & 0 & S3 & 11.9147 & 25.11583 & 0.2219 & 1.2332 \\
\hline & & 1 & S3 & 3.808867 & 32.75537 & 0.1903 & 1.2662 \\
\hline & \multirow[t]{2}{*}{0.7} & 0 & S3 & 8.932613 & 18.84478 & 0.1924 & 1.257 \\
\hline & & 1 & S3 & 2.921155 & 30.551 & 0.1972 & 1.286 \\
\hline & \multirow[t]{2}{*}{0.6} & 0 & S3 & 6.432 & 13.57994 & 0.1634 & 1.3096 \\
\hline & & 1 & S3 & 2.353216 & 29.12948 & 0.2153 & 1.2503 \\
\hline & \multirow[t]{2}{*}{0.59} & 0 & S3 & 6.20724 & 13.10625 & 0.1605 & 1.213 \\
\hline & & 1 & S3 & 2.313553 & 29.02918 & 0.2179 & 1.224 \\
\hline
\end{tabular}

*Where, 0 = network without DG, and 1 = network with DG

from the original mesh network. The performance of the ten manually reconfigured radial networks (viz. configuration number 1 to 10) with regard to active power loss, reactive power loss and voltage stability are compared to those of the optimal radial network obtained via the application of Kruskal's algorithm at base loading scenario is shown in Table 3. It can be clearly seen from the results furnished in Table 3 that the radial network configured through the application of Kruskal's maximal spanning tree algorithm gives better performance. Figure 7 shows the optimal radial network for base loading scenario obtained via the application of the proposed technique.

Similar to the computation and comparison carried out for the base loading scenario for the 30-node test system, identical procedures were applied to obtain, test for and verify the optimality of the radial networks computed by the proposed technique for all the different loading scenarios considered. Further, in order to reduce confusion, the computations were done considering descending order of loading scenario. Tables 4, 5, 6, 7 and 8 represent the simulation results showing the different manual switching configurations (resulting in radial networks) and the switching configuration obtained via the proposed technique and comparing its corresponding resulting values of L-index, P-loss, and Q-loss for the loading conditions at $90 \%, 80 \%, 70 \%, 60 \%$ and $59 \%$ of base load conditions, respectively. For each of the different loading scenarios considered, it is clearly visible from the results that the optimal network computed via Kruskal's algorithm results in the least amount of losses and most optimal voltage stability index value. For $90 \%$ base-load scenario the Kruskal's algorithm computed radial network as shown in Fig. 7, and Fig. 8 depicts the optimal radial networks obtained via application of Kruskal's maximal spanning tree algorithm

Table 3 Calculated values of L-index, P-loss, and Q-loss at base loading scenario

\begin{tabular}{|c|c|c|c|c|c|}
\hline Configuration No. & Switch configurations & P-loss (MW) & Q-loss (MVAr) & L-index (p.u.) & Time taken (seconds) \\
\hline 1 & $\mathrm{~S} 1, \mathrm{~S} 6, \mathrm{~S} 9, \mathrm{~S} 14, \mathrm{~S} 19, \mathrm{~S} 20, \mathrm{~S} 25, \mathrm{~S} 28, \mathrm{~S} 31, \mathrm{~S} 32, \mathrm{~S} 38, \mathrm{~S} 40$ & 70.5523 & 247.1022 & 0.9898 & Not applicable \\
\hline 2 & $\mathrm{~S} 4, \mathrm{~S} 5, \mathrm{~S} 6, \mathrm{~S} 10, \mathrm{~S} 14, \mathrm{~S} 19, \mathrm{~S} 20, \mathrm{~S} 25, \mathrm{~S} 28, \mathrm{~S} 31, \mathrm{~S} 32, \mathrm{~S} 38$ & 118.1715 & 352.0388 & 0.9849 & - do- \\
\hline 3 & $\mathrm{~S} 1, \mathrm{~S} 6, \mathrm{~S} 8, \mathrm{~S} 14, \mathrm{~S} 19, \mathrm{~S} 20, \mathrm{~S} 25, \mathrm{~S} 28, \mathrm{~S} 31, \mathrm{~S} 32, \mathrm{~S} 38, \mathrm{~S} 40$ & 61.7466 & 216.2223 & 0.9665 & -do- \\
\hline 4 & $\mathrm{~S} 4, \mathrm{~S} 6, \mathrm{~S} 7, \mathrm{~S} 10, \mathrm{~S} 14, \mathrm{~S} 19, \mathrm{~S} 20, \mathrm{~S} 25, \mathrm{~S} 28, \mathrm{~S} 35, \mathrm{~S} 32, \mathrm{~S} 38$ & 51.2592 & 171.6666 & 0.9004 & - do- \\
\hline 5 & $\mathrm{~S} 4, \mathrm{~S} 6, \mathrm{~S} 7, \mathrm{~S} 10, \mathrm{~S} 14, \mathrm{~S} 19, \mathrm{~S} 20, \mathrm{~S} 25, \mathrm{~S} 28, \mathrm{~S} 31, \mathrm{~S} 32, \mathrm{~S} 38$ & 49.6069 & 149.9626 & 0.8576 & - do- \\
\hline 6 & $\mathrm{~S} 4, \mathrm{~S} 6, \mathrm{~S} 9, \mathrm{~S} 10, \mathrm{~S} 14, \mathrm{~S} 19, \mathrm{~S} 20, \mathrm{~S} 25, \mathrm{~S} 28, \mathrm{~S} 31, \mathrm{~S} 32, \mathrm{~S} 38$ & 34.4377 & 88.6472 & 0.6468 & -do- \\
\hline 7 & $\mathrm{~S} 4, \mathrm{~S} 6, \mathrm{~S} 9, \mathrm{~S} 14, \mathrm{~S} 19, \mathrm{~S} 20, \mathrm{~S} 25, \mathrm{~S} 28, \mathrm{~S} 31, \mathrm{~S} 32, \mathrm{~S} 38, \mathrm{~S} 40$ & 33.1613 & 86.8368 & 0.6353 & -do- \\
\hline 8 & $\mathrm{~S} 3, \mathrm{~S} 6, \mathrm{~S} 8, \mathrm{~S} 14, \mathrm{~S} 19, \mathrm{~S} 20, \mathrm{~S} 23, \mathrm{~S} 28, \mathrm{~S} 31, \mathrm{~S} 32, \mathrm{~S} 38, \mathrm{~S} 40$ & 25.7642 & 86.7269 & 0.6056 & - do- \\
\hline 9 & $\mathrm{~S} 3, \mathrm{~S} 6, \mathrm{~S} 8, \mathrm{~S} 14, \mathrm{~S} 19, \mathrm{~S} 20, \mathrm{~S} 25, \mathrm{~S} 28, \mathrm{~S} 31, \mathrm{~S} 32, \mathrm{~S} 38, \mathrm{~S} 40$ & 25.6961 & 79.5294 & 0.5759 & - do- \\
\hline 10 & $\mathrm{~S} 3, \mathrm{~S} 6, \mathrm{~S} 8, \mathrm{~S} 14, \mathrm{~S} 20, \mathrm{~S} 23, \mathrm{~S} 26, \mathrm{~S} 28, \mathrm{~S} 31, \mathrm{~S} 32, \mathrm{~S} 38, \mathrm{~S} 40$ & 25.1826 & 77.6612 & 0.5656 & - do- \\
\hline Kruskal's & $\mathrm{S} 3, \mathrm{~S} 6, \mathrm{~S} 8, \mathrm{~S} 12, \mathrm{~S} 20, \mathrm{~S} 23, \mathrm{~S} 26, \mathrm{~S} 28, \mathrm{~S} 31, \mathrm{~S} 32, \mathrm{~S} 38, \mathrm{~S} 40$ & 25.0578 & 74.4049 & 0.5516 & 3.414651 \\
\hline
\end{tabular}




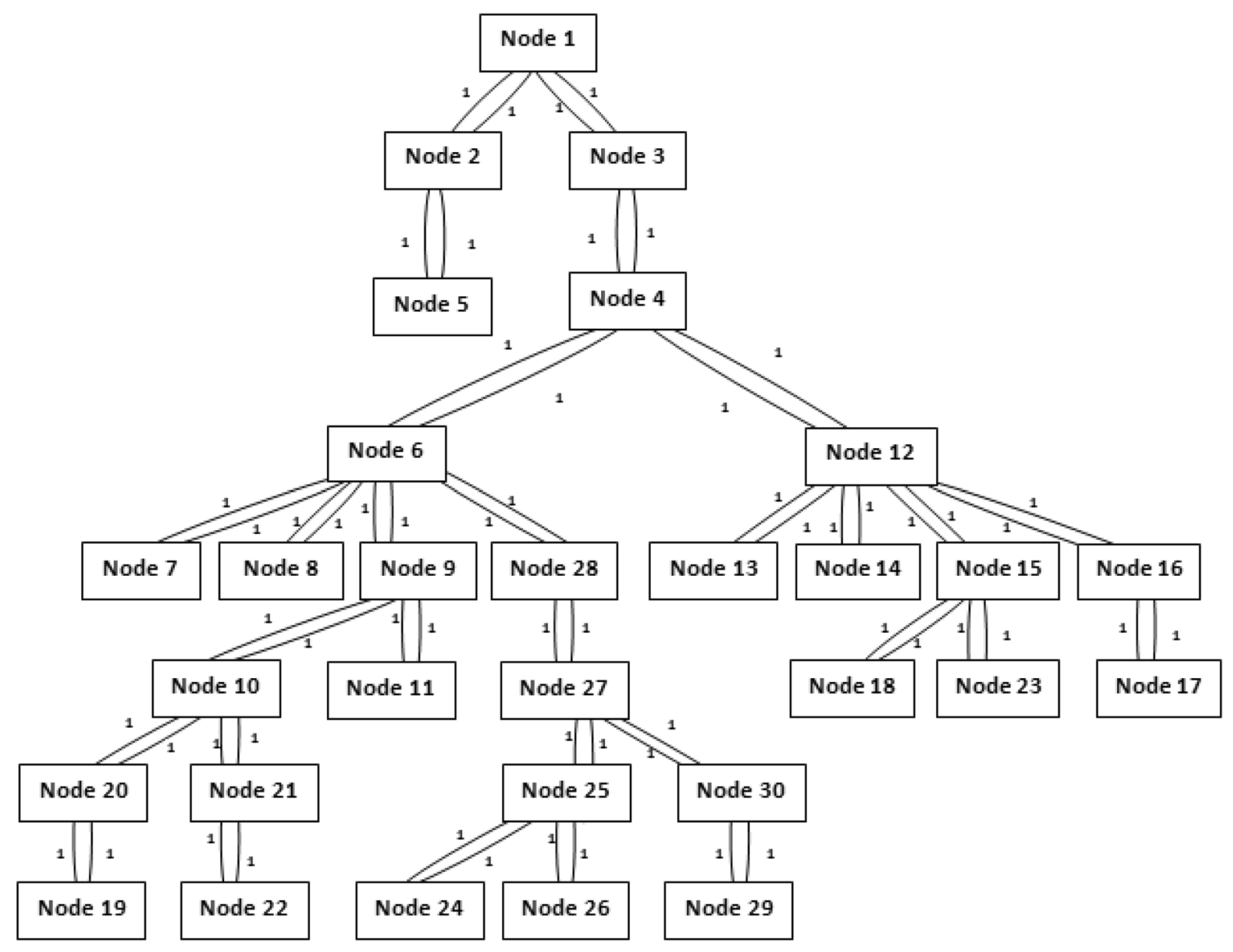

Fig. 7 Optimal radial network obtained by applying Kruskal's algorithm for base loading condition and 90\% base-load condition

Table 4 Calculated values of L-index, P-loss, and Q-loss at $90 \%$ of base load

\begin{tabular}{|c|c|c|c|c|c|}
\hline Configuration No. & Switch configurations & P-loss (MW) & Q-loss (MVAr) & L-index (p.u.) & Time taken (seconds) \\
\hline 1 & $\mathrm{~S} 1, \mathrm{~S} 6, \mathrm{~S} 9, \mathrm{~S} 14, \mathrm{~S} 19, \mathrm{~S} 20, \mathrm{~S} 25, \mathrm{~S} 28, \mathrm{~S} 31, \mathrm{~S} 32, \mathrm{~S} 38, \mathrm{~S} 40$ & 48.8007 & 162.6696 & 0.9519 & Not applicable \\
\hline 2 & S4,S5,S6,S10,S14,S19,S20,S25,S28,S31,S32,S38 & 77.1868 & 216.0878 & 0.9896 & - do- \\
\hline 3 & $\mathrm{~S} 1, \mathrm{~S} 6, \mathrm{~S} 8, \mathrm{~S} 14, \mathrm{~S} 19, \mathrm{~S} 20, \mathrm{~S} 25, \mathrm{~S} 28, \mathrm{~S} 31, \mathrm{~S} 32, \mathrm{~S} 38, \mathrm{~S} 40$ & 42.9753 & 142.4505 & 0.8725 & - do- \\
\hline 4 & S4,S6,S7,S10,S14,S19,S20,S25,S28,S35,S32,S38 & 38.0375 & 112.4931 & 0.7836 & - do- \\
\hline 5 & $\mathrm{~S} 4, \mathrm{~S} 6, \mathrm{~S} 7, \mathrm{~S} 10, \mathrm{~S} 14, \mathrm{~S} 19, \mathrm{~S} 20, \mathrm{~S} 25, \mathrm{~S} 28, \mathrm{~S} 31, \mathrm{~S} 32, \mathrm{~S} 38$ & 37.7379 & 104.5323 & 0.7579 & - do- \\
\hline 6 & $\mathrm{~S} 4, \mathrm{~S} 6, \mathrm{~S} 9, \mathrm{~S} 10, \mathrm{~S} 14, \mathrm{~S} 19, \mathrm{~S} 20, \mathrm{~S} 25, \mathrm{~S} 28, \mathrm{~S} 31, \mathrm{~S} 32, \mathrm{~S} 38$ & 26.3644 & 58.6465 & 0.5356 & - do- \\
\hline 7 & S4,S6,S9,S14,S19,S20,S25,S28,S31,S32,S38,S40 & 25.4732 & 58.9518 & 0.5316 & - do- \\
\hline 8 & $\mathrm{~S} 3, \mathrm{~S} 6, \mathrm{~S} 8, \mathrm{~S} 14, \mathrm{~S} 19, \mathrm{~S} 20, \mathrm{~S} 23, \mathrm{~S} 28, \mathrm{~S} 31, \mathrm{~S} 32, \mathrm{~S} 38, \mathrm{~S} 40$ & 19.6799 & 58.1736 & 0.4937 & - do- \\
\hline 9 & $\mathrm{~S} 3, \mathrm{~S} 6, \mathrm{~S} 8, \mathrm{~S} 14, \mathrm{~S} 19, \mathrm{~S} 20, \mathrm{~S} 25, \mathrm{~S} 28, \mathrm{~S} 31, \mathrm{~S} 32, \mathrm{~S} 38, \mathrm{~S} 40$ & 19.7355 & 53.9213 & 0.4728 & - do- \\
\hline 10 & $\mathrm{~S} 3, \mathrm{~S} 6, \mathrm{~S} 8, \mathrm{~S} 14, \mathrm{~S} 20, \mathrm{~S} 23, \mathrm{~S} 26, \mathrm{~S} 28, \mathrm{~S} 31, \mathrm{~S} 32, \mathrm{~S} 38, \mathrm{~S} 40$ & 19.3623 & 52.7668 & 0.4644 & - do- \\
\hline Kruskal's & $\mathrm{S} 3, \mathrm{~S} 6, \mathrm{~S} 8, \mathrm{~S} 12, \mathrm{~S} 20, \mathrm{~S} 23, \mathrm{~S} 26, \mathrm{~S} 28, \mathrm{~S} 31, \mathrm{~S} 32, \mathrm{~S} 37, \mathrm{~S} 40$ & 19.3111 & 50.4591 & 0.4531 & 3.699503 \\
\hline
\end{tabular}

at different loading scenarios of $80 \%, 70 \%, 60 \%$, and $59 \%$ of the base load, respectively. Additionally, from Tables 3, $4,5,6,7$ and 8 it may also be noticed that, as the loading level is reduced from 100 to $59 \%$ of base load there is a corresponding reduction in the L-index value. Thus, for the different loading scenarios considered here, the L-index value of 0.1501 p.u. at $59 \%$ of base load is the least value.
In order to further validate the optimality of the reconfigured radial network obtained via the proposed technique for a given DG-integrated mesh network for different time-varying loading conditions, the proposed approach is compared with a similar graph theoretic approach known as Edmond's algorithm from [11]. Since in [11], the work is primarily focused on obtaining 
Table 5 Calculated values of L-index, P-loss, and Q-loss at $80 \%$ of base load

\begin{tabular}{|c|c|c|c|c|c|}
\hline Configuration No. & Switch configurations & P-loss (MW) & Q-loss (MVAr) & L-index (p.u.) & Time taken (seconds) \\
\hline 1 & $\mathrm{~S} 1, \mathrm{~S} 6, \mathrm{~S} 9, \mathrm{~S} 14, \mathrm{~S} 19, \mathrm{~S} 20, \mathrm{~S} 25, \mathrm{~S} 28, \mathrm{~S} 31, \mathrm{~S} 32, \mathrm{~S} 38, \mathrm{~S} 40$ & 33.5666 & 103.4047 & 0.7940 & Not applicable \\
\hline 2 & $\mathrm{~S} 4, \mathrm{~S} 5, \mathrm{~S} 6, \mathrm{~S} 10, \mathrm{~S} 14, \mathrm{~S} 19, \mathrm{~S} 20, \mathrm{~S} 25, \mathrm{~S} 28, \mathrm{~S} 31, \mathrm{~S} 32, \mathrm{~S} 38$ & 53.0881 & 137.0095 & 0.9170 & -do- \\
\hline 3 & $\mathrm{~S} 1, \mathrm{~S} 6, \mathrm{~S} 8, \mathrm{~S} 14, \mathrm{~S} 19, \mathrm{~S} 20, \mathrm{~S} 25, \mathrm{~S} 28, \mathrm{~S} 31, \mathrm{~S} 32, \mathrm{~S} 38, \mathrm{~S} 40$ & 29.6122 & 89.7923 & 0.7321 & -do- \\
\hline 4 & $\mathrm{~S} 4, \mathrm{~S} 6, \mathrm{~S} 7, \mathrm{~S} 10, \mathrm{~S} 14, \mathrm{~S} 19, \mathrm{~S} 20, \mathrm{~S} 25, \mathrm{~S} 28, \mathrm{~S} 35, \mathrm{~S} 32, \mathrm{~S} 38$ & 28.0667 & 71.5817 & 0.6509 & -do- \\
\hline 5 & $\mathrm{~S} 4, \mathrm{~S} 6, \mathrm{~S} 7, \mathrm{~S} 10, \mathrm{~S} 14, \mathrm{~S} 19, \mathrm{~S} 20, \mathrm{~S} 25, \mathrm{~S} 28, \mathrm{~S} 31, \mathrm{~S} 32, \mathrm{~S} 38$ & 28.0354 & 67.49774 & 0.6323 & -do- \\
\hline 6 & $\mathrm{~S} 4, \mathrm{~S} 6, \mathrm{~S} 9, \mathrm{~S} 10, \mathrm{~S} 14, \mathrm{~S} 19, \mathrm{~S} 20, \mathrm{~S} 25, \mathrm{~S} 28, \mathrm{~S} 31, \mathrm{~S} 32, \mathrm{~S} 38$ & 19.6768 & 33.9852 & 0.4159 & -do- \\
\hline 7 & $\mathrm{~S} 4, \mathrm{~S} 6, \mathrm{~S} 9, \mathrm{~S} 14, \mathrm{~S} 19, \mathrm{~S} 20, \mathrm{~S} 25, \mathrm{~S} 28, \mathrm{~S} 31, \mathrm{~S} 32, \mathrm{~S} 38, \mathrm{~S} 40$ & 19.0307 & 35.6440 & 0.4187 & -do- \\
\hline 8 & $\mathrm{~S} 3, \mathrm{~S} 6, \mathrm{~S} 8, \mathrm{~S} 14, \mathrm{~S} 19, \mathrm{~S} 20, \mathrm{~S} 23, \mathrm{~S} 28, \mathrm{~S} 31, \mathrm{~S} 32, \mathrm{~S} 38, \mathrm{~S} 40$ & 14.7383 & 35.4605 & 0.3805 & -do- \\
\hline 9 & $\mathrm{~S} 3, \mathrm{~S} 6, \mathrm{~S} 8, \mathrm{~S} 14, \mathrm{~S} 19, \mathrm{~S} 20, \mathrm{~S} 25, \mathrm{~S} 28, \mathrm{~S} 31, \mathrm{~S} 32, \mathrm{~S} 38, \mathrm{~S} 40$ & 14.8343 & 32.9197 & 0.3667 & -do- \\
\hline 10 & $\mathrm{~S} 3, \mathrm{~S} 6, \mathrm{~S} 8, \mathrm{~S} 14, \mathrm{~S} 20, \mathrm{~S} 23, \mathrm{~S} 26, \mathrm{~S} 28, \mathrm{~S} 31, \mathrm{~S} 32, \mathrm{~S} 38, \mathrm{~S} 40$ & 14.6158 & 32.4997 & 0.3617 & -do- \\
\hline Kruskal's & $\mathrm{S} 3, \mathrm{~S} 6, \mathrm{~S} 8, \mathrm{~S} 12, \mathrm{~S} 20, \mathrm{~S} 24, \mathrm{~S} 26, \mathrm{~S} 28, \mathrm{~S} 31, \mathrm{~S} 32, \mathrm{~S} 37, \mathrm{~S} 40$ & 14.6471 & 31.1463 & 0.3552 & 3.714237 \\
\hline
\end{tabular}

Table 6 Calculated values of L-index, P-loss, and Q-loss at 70\% of base load

\begin{tabular}{|c|c|c|c|c|c|}
\hline Configuration No. & Switch configurations & P-loss (MW) & Q-loss (MVAr) & L-index (p.u.) & Time taken (seconds) \\
\hline 1 & $\mathrm{~S} 1, \mathrm{~S} 6, \mathrm{~S} 9, \mathrm{~S} 14, \mathrm{~S} 19, \mathrm{~S} 20, \mathrm{~S} 25, \mathrm{~S} 28, \mathrm{~S} 31, \mathrm{~S} 32, \mathrm{~S} 38, \mathrm{~S} 40$ & 22.4141 & 59.9081 & 0.6220 & Not applicable \\
\hline 2 & S4,S5,S6,S10,S14,S19,S20,S25,S28,S31,S32,S38 & 36.3355 & 82.3800 & 0.7866 & - do- \\
\hline 3 & $\mathrm{~S} 1, \mathrm{~S} 6, \mathrm{~S} 8, \mathrm{~S} 14, \mathrm{~S} 19, \mathrm{~S} 20, \mathrm{~S} 25, \mathrm{~S} 28, \mathrm{~S} 31, \mathrm{~S} 32, \mathrm{~S} 38, \mathrm{~S} 40$ & 19.7677 & 50.8835 & 0.5557 & - do- \\
\hline 4 & $\mathrm{~S} 4, \mathrm{~S} 6, \mathrm{~S} 7, \mathrm{~S} 10, \mathrm{~S} 14, \mathrm{~S} 19, \mathrm{~S} 20, \mathrm{~S} 25, \mathrm{~S} 28, \mathrm{~S} 35, \mathrm{~S} 32, \mathrm{~S} 38$ & 20.1505 & 39.9141 & 0.4983 & - do- \\
\hline 5 & S4,S6,S7,S10,S14,S19,S20,S25,S28,S31,S32,S38 & 20.1878 & 37.5699 & 0.4853 & - do- \\
\hline 6 & $\mathrm{~S} 4, \mathrm{~S} 6, \mathrm{~S} 9, \mathrm{~S} 10, \mathrm{~S} 14, \mathrm{~S} 19, \mathrm{~S} 20, \mathrm{~S} 25, \mathrm{~S} 28, \mathrm{~S} 31, \mathrm{~S} 32, \mathrm{~S} 38$ & 14.2110 & 13.9257 & 0.2945 & - do- \\
\hline 7 & S4,S6,S9,S14,S19,S20,S25,S28,S31,S32,S38,S40 & 13.7222 & 16.4632 & 0.3017 & -do- \\
\hline 8 & $\mathrm{~S} 3, \mathrm{~S} 6, \mathrm{~S} 8, \mathrm{~S} 14, \mathrm{~S} 19, \mathrm{~S} 20, \mathrm{~S} 23, \mathrm{~S} 28, \mathrm{~S} 31, \mathrm{~S} 32, \mathrm{~S} 38, \mathrm{~S} 40$ & 10.7467 & 17.3263 & 0.2692 & - do- \\
\hline 9 & S3,S6,S8,S14,S19,S20,S25,S28,S31,S32,S38,S40 & 10.8475 & 15.8539 & 0.2615 & - do- \\
\hline 10 & S3,S6,S8,S14,S20,S23,S26,S28,S31,S32,S38,S40 & 10.6613 & 15.5266 & 0.2570 & - do- \\
\hline Kruskal's & $\mathrm{S} 3, \mathrm{~S} 6, \mathrm{~S} 8, \mathrm{~S} 12, \mathrm{~S} 20, \mathrm{~S} 24, \mathrm{~S} 26, \mathrm{~S} 28, \mathrm{~S} 31, \mathrm{~S} 32, \mathrm{~S} 37, \mathrm{~S} 40$ & 10.7011 & 14.5975 & 0.2526 & 3.429168 \\
\hline
\end{tabular}

Table 7 Calculated values of L-index, P-loss, and Q-loss at $60 \%$ of base load

\begin{tabular}{|c|c|c|c|c|c|}
\hline Configuration No. & Switch configurations & P-loss (MW) & Q-loss (MVAr) & L-index (p.u.) & Time taken (seconds) \\
\hline 1 & $\mathrm{~S} 1, \mathrm{~S} 6, \mathrm{~S} 9, \mathrm{~S} 14, \mathrm{~S} 19, \mathrm{~S} 20, \mathrm{~S} 25, \mathrm{~S} 28, \mathrm{~S} 31, \mathrm{~S} 32, \mathrm{~S} 38, \mathrm{~S} 40$ & 14.2212 & 27.8497 & 0.4202 & Not applicable \\
\hline 2 & $\mathrm{~S} 4, \mathrm{~S} 5, \mathrm{~S} 6, \mathrm{~S} 10, \mathrm{~S} 14, \mathrm{~S} 19, \mathrm{~S} 20, \mathrm{~S} 25, \mathrm{~S} 28, \mathrm{~S} 31, \mathrm{~S} 32, \mathrm{~S} 38$ & 24.1677 & 42.87753 & 0.6082 & -do- \\
\hline 3 & $\mathrm{~S} 1, \mathrm{~S} 6, \mathrm{~S} 8, \mathrm{~S} 14, \mathrm{~S} 19, \mathrm{~S} 20, \mathrm{~S} 25, \mathrm{~S} 28, \mathrm{~S} 31, \mathrm{~S} 32, \mathrm{~S} 38, \mathrm{~S} 40$ & 12.5227 & 22.1387 & 0.3615 & -do- \\
\hline 4 & $\mathrm{~S} 4, \mathrm{~S} 6, \mathrm{~S} 7, \mathrm{~S} 10, \mathrm{~S} 14, \mathrm{~S} 19, \mathrm{~S} 20, \mathrm{~S} 25, \mathrm{~S} 28, \mathrm{~S} 35, \mathrm{~S} 32, \mathrm{~S} 38$ & 13.9224 & 15.3297 & 0.3384 & -do- \\
\hline 5 & $\mathrm{~S} 4, \mathrm{~S} 6, \mathrm{~S} 7, \mathrm{~S} 10, \mathrm{~S} 14, \mathrm{~S} 19, \mathrm{~S} 20, \mathrm{~S} 25, \mathrm{~S} 28, \mathrm{~S} 31, \mathrm{~S} 32, \mathrm{~S} 38$ & 13.9643 & 13.8164 & 0.3304 & -do- \\
\hline 6 & $\mathrm{~S} 4, \mathrm{~S} 6, \mathrm{~S} 9, \mathrm{~S} 10, \mathrm{~S} 14, \mathrm{~S} 19, \mathrm{~S} 20, \mathrm{~S} 25, \mathrm{~S} 28, \mathrm{~S} 31, \mathrm{~S} 32, \mathrm{~S} 38$ & 9.8445 & -2.0562 & 0.1853 & -do- \\
\hline 7 & $\mathrm{~S} 4, \mathrm{~S} 6, \mathrm{~S} 9, \mathrm{~S} 14, \mathrm{~S} 19, \mathrm{~S} 20, \mathrm{~S} 25, \mathrm{~S} 28, \mathrm{~S} 31, \mathrm{~S} 32, \mathrm{~S} 38, \mathrm{~S} 40$ & 9.4569 & 1.0533 & 0.1917 & -do- \\
\hline 8 & $\mathrm{~S} 3, \mathrm{~S} 6, \mathrm{~S} 8, \mathrm{~S} 14, \mathrm{~S} 19, \mathrm{~S} 20, \mathrm{~S} 23, \mathrm{~S} 28, \mathrm{~S} 31, \mathrm{~S} 32, \mathrm{~S} 38, \mathrm{~S} 40$ & 7.5801 & 3.0298 & 0.1678 & -do- \\
\hline 9 & $\mathrm{~S} 3, \mathrm{~S} 6, \mathrm{~S} 8, \mathrm{~S} 14, \mathrm{~S} 19, \mathrm{~S} 20, \mathrm{~S} 25, \mathrm{~S} 28, \mathrm{~S} 31, \mathrm{~S} 32, \mathrm{~S} 38, \mathrm{~S} 40$ & 7.6700 & 2.2432 & 0.1655 & -do- \\
\hline 10 & $\mathrm{~S} 3, \mathrm{~S} 6, \mathrm{~S} 8, \mathrm{~S} 14, \mathrm{~S} 20, \mathrm{~S} 23, \mathrm{~S} 26, \mathrm{~S} 28, \mathrm{~S} 31, \mathrm{~S} 32, \mathrm{~S} 38, \mathrm{~S} 40$ & 7.5457 & 2.1409 & 0.1628 & -do- \\
\hline Kruskal's & $\mathrm{S} 3, \mathrm{~S} 6, \mathrm{~S} 8, \mathrm{~S} 12, \mathrm{~S} 20, \mathrm{~S} 24, \mathrm{~S} 26, \mathrm{~S} 28, \mathrm{~S} 31, \mathrm{~S} 32, \mathrm{~S} 37, \mathrm{~S} 40$ & 7.5355 & 1.2317 & 0.1574 & 3.458026 \\
\hline
\end{tabular}

the optimal radial network for an electrical system for constant load and without DG integration, we are unable to properly compare the performance of the algorithms against each other. Thus, in order to properly compare the performance of the algorithms under similar conditions, we have also studied Edmond's algorithm as well and applied it to find the optimal radial network configurations of the test system for different time-varying loading conditions. The performance analysis based on the comparison of the active and reactive 
Table 8 Calculated values of L-index, P-loss, and Q-loss at 59\% of base load

\begin{tabular}{|c|c|c|c|c|c|}
\hline Configuration No. & Switch configurations & P-loss (MW) & Q-loss (MVAr) & L-index (p.u.) & Time taken (seconds) \\
\hline 1 & $\mathrm{~S} 1, \mathrm{~S} 6, \mathrm{~S} 9, \mathrm{~S} 14, \mathrm{~S} 19, \mathrm{~S} 20, \mathrm{~S} 25, \mathrm{~S} 28, \mathrm{~S} 31, \mathrm{~S} 32, \mathrm{~S} 38, \mathrm{~S} 40$ & 13.5379 & 25.1698 & 0.3995 & Not applicable \\
\hline 2 & $\mathrm{~S} 4, \mathrm{~S} 5, \mathrm{~S} 6, \mathrm{~S} 10, \mathrm{~S} 14, \mathrm{~S} 19, \mathrm{~S} 20, \mathrm{~S} 25, \mathrm{~S} 28, \mathrm{~S} 31, \mathrm{~S} 32, \mathrm{~S} 38$ & 23.1476 & 39.5725 & 0.5884 & - do- \\
\hline 3 & $\mathrm{~S} 1, \mathrm{~S} 6, \mathrm{~S} 8, \mathrm{~S} 14, \mathrm{~S} 19, \mathrm{~S} 20, \mathrm{~S} 25, \mathrm{~S} 28, \mathrm{~S} 31, \mathrm{~S} 32, \mathrm{~S} 38, \mathrm{~S} 40$ & 11.9188 & 19.7356 & 0.3423 & - do- \\
\hline 4 & $\mathrm{~S} 4, \mathrm{~S} 6, \mathrm{~S} 7, \mathrm{~S} 10, \mathrm{~S} 14, \mathrm{~S} 19, \mathrm{~S} 20, \mathrm{~S} 25, \mathrm{~S} 28, \mathrm{~S} 35, \mathrm{~S} 32, \mathrm{~S} 38$ & 13.3833 & 13.2125 & 0.3230 & - do- \\
\hline 5 & $\mathrm{~S} 4, \mathrm{~S} 6, \mathrm{~S} 7, \mathrm{~S} 10, \mathrm{~S} 14, \mathrm{~S} 19, \mathrm{~S} 20, \mathrm{~S} 25, \mathrm{~S} 28, \mathrm{~S} 31, \mathrm{~S} 32, \mathrm{~S} 38$ & 13.4240 & 11.7519 & 0.3155 & - do- \\
\hline 6 & $\mathrm{~S} 4, \mathrm{~S} 6, \mathrm{~S} 9, \mathrm{~S} 10, \mathrm{~S} 14, \mathrm{~S} 19, \mathrm{~S} 20, \mathrm{~S} 25, \mathrm{~S} 28, \mathrm{~S} 31, \mathrm{~S} 32, \mathrm{~S} 38$ & 9.4645 & -3.4463 & 0.1760 & - do- \\
\hline 7 & $\mathrm{~S} 4, \mathrm{~S} 6, \mathrm{~S} 9, \mathrm{~S} 14, \mathrm{~S} 19, \mathrm{~S} 20, \mathrm{~S} 25, \mathrm{~S} 28, \mathrm{~S} 31, \mathrm{~S} 32, \mathrm{~S} 38, \mathrm{~S} 40$ & 9.0848 & -0.2919 & 0.1818 & - do- \\
\hline 8 & $\mathrm{~S} 3, \mathrm{~S} 6, \mathrm{~S} 8, \mathrm{~S} 14, \mathrm{~S} 19, \mathrm{~S} 20, \mathrm{~S} 23, \mathrm{~S} 28, \mathrm{~S} 31, \mathrm{~S} 32, \mathrm{~S} 38, \mathrm{~S} 40$ & 7.3051 & 1.7908 & 0.1588 & - do- \\
\hline 9 & $\mathrm{~S} 3, \mathrm{~S} 6, \mathrm{~S} 8, \mathrm{~S} 14, \mathrm{~S} 19, \mathrm{~S} 20, \mathrm{~S} 25, \mathrm{~S} 28, \mathrm{~S} 31, \mathrm{~S} 32, \mathrm{~S} 38, \mathrm{~S} 40$ & 7.3936 & 1.0576 & 0.1569 & - do- \\
\hline 10 & $\mathrm{~S} 3, \mathrm{~S} 6, \mathrm{~S} 8, \mathrm{~S} 14, \mathrm{~S} 20, \mathrm{~S} 23, \mathrm{~S} 26, \mathrm{~S} 28, \mathrm{~S} 31, \mathrm{~S} 32, \mathrm{~S} 38, \mathrm{~S} 40$ & 7.2745 & 0.9728 & 0.1544 & - do- \\
\hline Kruskal's & $\mathrm{S} 3, \mathrm{~S} 6, \mathrm{~S} 8, \mathrm{~S} 12, \mathrm{~S} 20, \mathrm{~S} 24, \mathrm{~S} 26, \mathrm{~S} 28, \mathrm{~S} 31, \mathrm{~S} 32, \mathrm{~S} 37, \mathrm{~S} 40$ & 7.2943 & 0.18182 & 0.1501 & 3.218805 \\
\hline
\end{tabular}

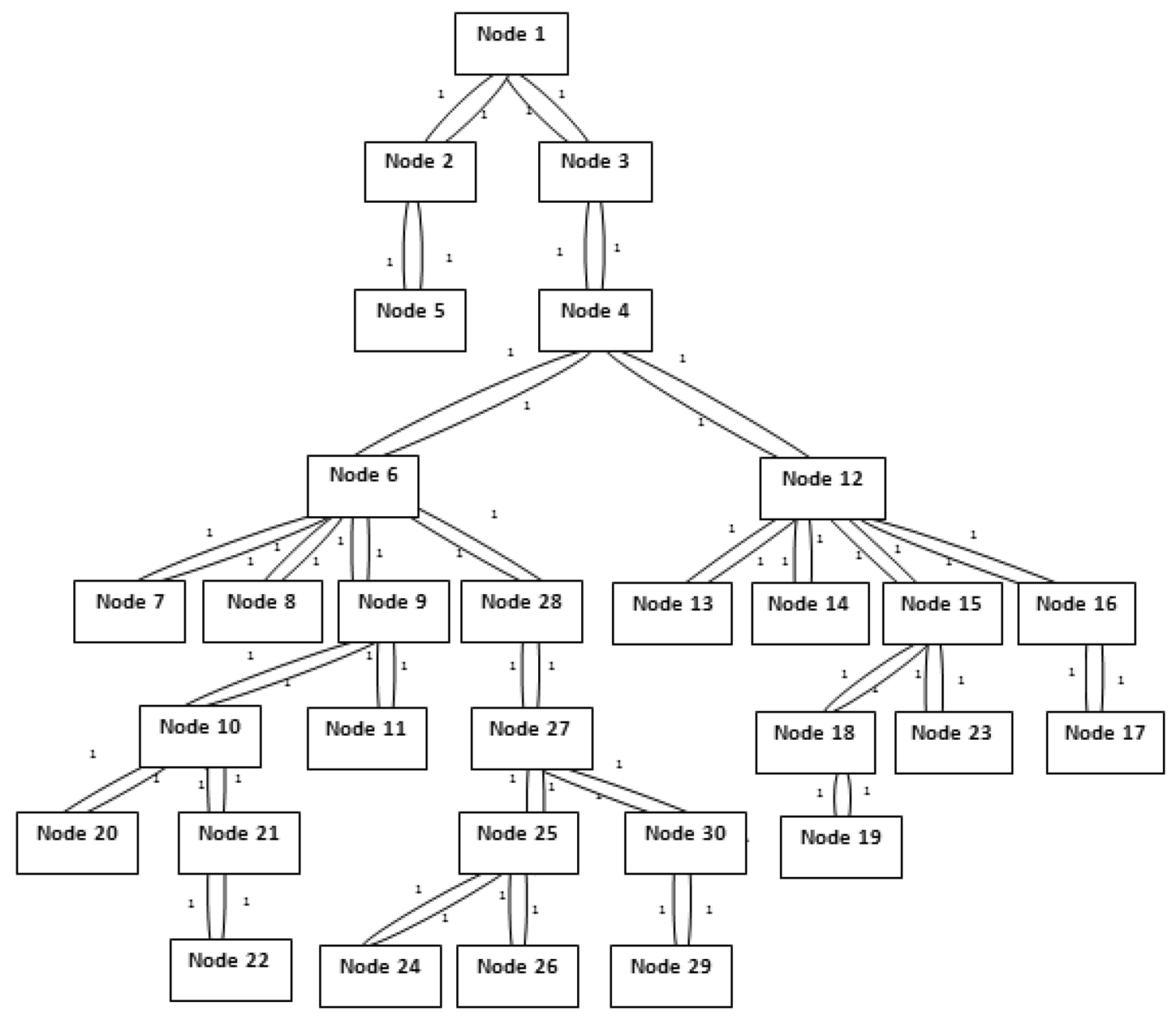

Fig. 8 Optimal radial network obtained by applying Kruskal's algorithm for the cases with $80 \%, 70 \%, 60 \%$ and $59 \%$ of base-load condition

power loss and the voltage stability index of the respective optimal radial networks obtained via application of Kruskal's algorithm and Edmond's algorithm for different time-varying loading scenarios for the test system are summarily tabulated and presented in Table 9. The impact DG integration has on the network such as minimization of the active and reactive power losses and the corresponding improvement in the voltage stability 
index (L-index) can also be observed from Table 9. Furthermore, it can be observed from Table 9 that in the case of finding an optimal radial network for an electrical network without DG integration, similar to [11] the performance of Edmond's algorithm outshines the performance of Kruskal's algorithm for base-load and $90 \%$ loading conditions, but when the load is less or equal $80 \%$ of the nominal load, the Kruskal's algorithm is superior to the Edmond's algorithm. As for when DG integrated networks are considered, the performance of Kruskal's algorithm is much better than that of Edmond's algorithm in finding the optimal radial network for all the different varying loading scenarios considered. The results obtained clearly indicate that for a DG integrated network, the optimal radial networks computed via the application of Kruskal's maximal spanning tree algorithm have lower losses and better L-index values for all the different time-varying loading scenarios considered.

The application of Kruskal's algorithm to obtain optimal radial networks from DG integrated meshed networks under time-varying load was further experimented on a robust test systems considering a modified IEEE-14 node test system. The results of the computations are furnished below in detail in tabular form in Table 10.

\section{Conclusion}

The process of finding the optimal spanning tree of a mesh-connected network through manual procedure involves a lot of labour and time and becomes increasing difficult for networks containing large amounts of nodes and edges. In an electrical network with distributed generation the process becomes more complicated due to the introduction of the phenomenon of bi-directional flow of power. However, unlike manual operation, the use of graph theory techniques makes it easier to compute tasks such as finding the optimal spanning tree quickly and accurately, and by making slight adjustments, the complexity in DG integrated networks is also greatly reduced. In this paper, the performance of Kruskal's maximal spanning tree algorithm in obtaining optimal radial networks from DG integrated mesh networks was investigated. The proposed technique has been demonstrated in detail on a

Table 9 Comparison of the results of the network with and without DG using Kruskal's and Edmond's Algorithms

\begin{tabular}{|c|c|c|c|c|c|c|c|}
\hline DG status* & Algorithm used & Loading (p.u.) & $\begin{array}{l}\text { Network configuration obtained after running } \\
\text { the algorithm (switches open) }\end{array}$ & Ploss (MW) & Qloss (Mvar) & L-index & Time(s) \\
\hline 0 & Kruskal's & 1 & $\mathrm{~S} 3, \mathrm{~S} 6, \mathrm{~S} 8, \mathrm{~S} 12, \mathrm{~S} 20, \mathrm{~S} 23, \mathrm{~S} 26, \mathrm{~S} 29, \mathrm{~S} 31, \mathrm{~S} 32, \mathrm{~S} 39, \mathrm{~S} 40$ & 29.0571 & 91.4282 & 0.6358 & 3.9426 \\
\hline 1 & & & $\mathrm{~S} 3, \mathrm{~S} 6, \mathrm{~S} 8, \mathrm{~S} 12, \mathrm{~S} 20, \mathrm{~S} 23, \mathrm{~S} 26, \mathrm{~S} 28, \mathrm{~S} 31, \mathrm{~S} 32, \mathrm{~S} 38, \mathrm{~S} 40$ & 25.0578 & 74.4049 & 0.5516 & 3.4146 \\
\hline 0 & Edmond's & & S3,S6,S8,S12,S20,S24,S26,S29,S32,S35,S39,S40 & 28.9324 & 91.0193 & 0.6337 & 2.0084 \\
\hline 1 & & & $\mathrm{~S} 3, \mathrm{~S} 6, \mathrm{~S} 8, \mathrm{~S} 12, \mathrm{~S} 20, \mathrm{~S} 24, \mathrm{~S} 26, \mathrm{~S} 28, \mathrm{~S} 32, \mathrm{~S} 35, \mathrm{~S} 38, \mathrm{~S} 40$ & 25.4246 & 77.2677 & 0.5650 & 1.7273 \\
\hline 0 & Kruskal's & 0.9 & $\mathrm{~S} 3, \mathrm{~S} 6, \mathrm{~S} 8, \mathrm{~S} 12, \mathrm{~S} 20, \mathrm{~S} 23, \mathrm{~S} 26, \mathrm{~S} 29, \mathrm{~S} 31, \mathrm{~S} 32, \mathrm{~S} 39, \mathrm{~S} 40$ & 23.1419 & 67.0876 & 0.5543 & 3.5221 \\
\hline 1 & & & $\mathrm{~S} 3, \mathrm{~S} 6, \mathrm{~S} 8, \mathrm{~S} 12, \mathrm{~S} 20, \mathrm{~S} 23, \mathrm{~S} 26, \mathrm{~S} 28, \mathrm{~S} 31, \mathrm{~S} 32, \mathrm{~S} 37, \mathrm{~S} 40$ & 19.3111 & 50.4591 & 0.4531 & 3.6995 \\
\hline 0 & Edmond's & & $\mathrm{S} 3, \mathrm{~S} 6, \mathrm{~S} 8, \mathrm{~S} 12, \mathrm{~S} 20, \mathrm{~S} 24, \mathrm{~S} 26, \mathrm{~S} 29, \mathrm{~S} 31, \mathrm{~S} 35, \mathrm{~S} 39, \mathrm{~S} 40$ & 14.6951 & 32.0598 & 0.3607 & 1.9451 \\
\hline 1 & & & $\mathrm{~S} 3, \mathrm{~S} 6, \mathrm{~S} 8, \mathrm{~S} 12, \mathrm{~S} 20, \mathrm{~S} 24, \mathrm{~S} 26, \mathrm{~S} 28, \mathrm{~S} 32, \mathrm{~S} 35, \mathrm{~S} 38, \mathrm{~S} 40$ & 19.5942 & 52.7367 & 0.4659 & 1.7554 \\
\hline 0 & Kruskal's & 0.8 & $\mathrm{~S} 3, \mathrm{~S} 6, \mathrm{~S} 8, \mathrm{~S} 12, \mathrm{~S} 20, \mathrm{~S} 24, \mathrm{~S} 26, \mathrm{~S} 28, \mathrm{~S} 31, \mathrm{~S} 32, \mathrm{~S} 37, \mathrm{~S} 40$ & 17.3907 & 42.4304 & 0.4403 & 4.1016 \\
\hline 1 & & & $\mathrm{~S} 3, \mathrm{~S} 6, \mathrm{~S} 8, \mathrm{~S} 12, \mathrm{~S} 20, \mathrm{~S} 24, \mathrm{~S} 26, \mathrm{~S} 28, \mathrm{~S} 31, \mathrm{~S} 32, \mathrm{~S} 37, \mathrm{~S} 40$ & 14.6471 & 31.1463 & 0.3552 & 3.7142 \\
\hline 0 & Edmond's & & $\mathrm{S} 3, \mathrm{~S} 6, \mathrm{~S} 8, \mathrm{~S} 12, \mathrm{~S} 20, \mathrm{~S} 24, \mathrm{~S} 26, \mathrm{~S} 28, \mathrm{~S} 32, \mathrm{~S} 36, \mathrm{~S} 38, \mathrm{~S} 40$ & 22.5262 & 64.1162 & 0.5375 & 1.7988 \\
\hline 1 & & & $\mathrm{~S} 3, \mathrm{~S} 6, \mathrm{~S} 8, \mathrm{~S} 12, \mathrm{~S} 20, \mathrm{~S} 24, \mathrm{~S} 26, \mathrm{~S} 28, \mathrm{~S} 32, \mathrm{~S} 36, \mathrm{~S} 38, \mathrm{~S} 40$ & 22.5262 & 64.1162 & 0.5375 & 1.7988 \\
\hline 0 & Kruskal's & 0.7 & $\mathrm{~S} 3, \mathrm{~S} 6, \mathrm{~S} 8, \mathrm{~S} 12, \mathrm{~S} 20, \mathrm{~S} 24, \mathrm{~S} 26, \mathrm{~S} 28, \mathrm{~S} 31, \mathrm{~S} 32, \mathrm{~S} 39, \mathrm{~S} 40$ & 12.7263 & 23.1052 & 0.3274 & 3.8004 \\
\hline 1 & & & $\mathrm{~S} 3, \mathrm{~S} 6, \mathrm{~S} 8, \mathrm{~S} 12, \mathrm{~S} 20, \mathrm{~S} 24, \mathrm{~S} 26, \mathrm{~S} 28, \mathrm{~S} 31, \mathrm{~S} 32, \mathrm{~S} 37, \mathrm{~S} 40$ & 10.7011 & 14.5975 & 0.2526 & 3.4291 \\
\hline 0 & Edmond's & & $\mathrm{S} 3, \mathrm{~S} 6, \mathrm{~S} 8, \mathrm{~S} 12, \mathrm{~S} 20, \mathrm{~S} 23, \mathrm{~S} 26, \mathrm{~S} 29, \mathrm{~S} 31, \mathrm{~S} 32, \mathrm{~S} 39, \mathrm{~S} 40$ & 12.9484 & 24.2187 & 0.3366 & 2.3917 \\
\hline 1 & & & $\mathrm{~S} 3, \mathrm{~S} 6, \mathrm{~S} 8, \mathrm{~S} 12, \mathrm{~S} 20, \mathrm{~S} 24, \mathrm{~S} 26, \mathrm{~S} 28, \mathrm{~S} 32, \mathrm{~S} 36, \mathrm{~S} 39, \mathrm{~S} 40$ & 10.7426 & 15.1022 & 0.2561 & 2.6270 \\
\hline 0 & Kruskal's & 0.6 & $\mathrm{~S} 3, \mathrm{~S} 6, \mathrm{~S} 8, \mathrm{~S} 12, \mathrm{~S} 20, \mathrm{~S} 24, \mathrm{~S} 26, \mathrm{~S} 28, \mathrm{~S} 31, \mathrm{~S} 32, \mathrm{~S} 39, \mathrm{~S} 40$ & 9.0934 & 7.7613 & 0.2208 & 3.8352 \\
\hline 1 & & & $\mathrm{~S} 3, \mathrm{~S} 6, \mathrm{~S} 8, \mathrm{~S} 12, \mathrm{~S} 20, \mathrm{~S} 24, \mathrm{~S} 26, \mathrm{~S} 28, \mathrm{~S} 31, \mathrm{~S} 32, \mathrm{~S} 37, \mathrm{~S} 40$ & 7.5355 & 1.2317 & 0.1574 & 3.4580 \\
\hline 0 & Edmond's & & $\mathrm{S} 3, \mathrm{~S} 6, \mathrm{~S} 8, \mathrm{~S} 12, \mathrm{~S} 20, \mathrm{~S} 23, \mathrm{~S} 26, \mathrm{~S} 29, \mathrm{~S} 31, \mathrm{~S} 32, \mathrm{~S} 39, \mathrm{~S} 40$ & 9.2295 & 8.4923 & 0.2273 & 2.2605 \\
\hline 1 & & & $\mathrm{~S} 3, \mathrm{~S} 6, \mathrm{~S} 8, \mathrm{~S} 12, \mathrm{~S} 20, \mathrm{~S} 24, \mathrm{~S} 26, \mathrm{~S} 28, \mathrm{~S} 32, \mathrm{~S} 36, \mathrm{~S} 39, \mathrm{~S} 40$ & 7.5824 & 1.414 & 0.1592 & 2.2698 \\
\hline 0 & Kruskal's & 0.59 & $\mathrm{~S} 3, \mathrm{~S} 6, \mathrm{~S} 8, \mathrm{~S} 12, \mathrm{~S} 20, \mathrm{~S} 24, \mathrm{~S} 26, \mathrm{~S} 28, \mathrm{~S} 31, \mathrm{~S} 32, \mathrm{~S} 39, \mathrm{~S} 40$ & 8.773 & 6.4046 & 0.2107 & 2.6388 \\
\hline 1 & & & $\mathrm{~S} 3, \mathrm{~S} 6, \mathrm{~S} 8, \mathrm{~S} 12, \mathrm{~S} 20, \mathrm{~S} 24, \mathrm{~S} 26, \mathrm{~S} 28, \mathrm{~S} 31, \mathrm{~S} 32, \mathrm{~S} 37, \mathrm{~S} 40$ & 7.2943 & 0.18182 & 0.1501 & 3.2188 \\
\hline 0 & Edmond's & & $\mathrm{S} 3, \mathrm{~S} 6, \mathrm{~S} 8, \mathrm{~S} 12, \mathrm{~S} 20, \mathrm{~S} 23, \mathrm{~S} 26, \mathrm{~S} 29, \mathrm{~S} 31, \mathrm{~S} 32, \mathrm{~S} 39, \mathrm{~S} 40$ & 8.9018 & 7.1029 & 0.2169 & 2.3346 \\
\hline 1 & & & $\mathrm{~S} 3, \mathrm{~S} 6, \mathrm{~S} 8, \mathrm{~S} 12, \mathrm{~S} 20, \mathrm{~S} 24, \mathrm{~S} 26, \mathrm{~S} 28, \mathrm{~S} 32, \mathrm{~S} 36, \mathrm{~S} 39, \mathrm{~S} 40$ & 9.6822 & 0.72294 & 0.1965 & 4.0848 \\
\hline
\end{tabular}

*Where, 0 = network without DG, and 1 = network with DG 
Table 10 Comparison of the radial networks obtained via manual switching and via application of Kruskal algorithm for a 14-node test system with and without DG integration

\begin{tabular}{|c|c|c|c|c|c|c|c|}
\hline Algorithm used & Loading (p.u.) & DG status* & $\begin{array}{l}\text { Network configuration obtained after } \\
\text { running the algorithm (switches open) }\end{array}$ & Ploss (MW) & Qloss (Mvar) & L-index & Time(s) \\
\hline \multirow[t]{10}{*}{ Kruskal's } & 1 & 0 & $\mathrm{~S} 5, \mathrm{~S} 6, \mathrm{~S} 7, \mathrm{~S} 9, \mathrm{~S} 18, \mathrm{~S} 19, \mathrm{~S} 20$ & 18.93 & 59.928 & 0.4801 & 1.667 \\
\hline & & 1 & $\mathrm{~S} 5, \mathrm{~S} 6, \mathrm{~S} 7, \mathrm{~S} 9, \mathrm{~S} 17, \mathrm{~S} 18, \mathrm{~S} 19$ & 15.587 & 43.543 & 0.3767 & 1.5895 \\
\hline & 0.9 & 0 & $\mathrm{~S} 5, \mathrm{~S} 6, \mathrm{~S} 7, \mathrm{S9}, \mathrm{S} 18, \mathrm{~S} 19, \mathrm{~S} 20$ & 14.806 & 42.870 & 0.4033 & 1.6001 \\
\hline & & 1 & $\mathrm{~S} 5, \mathrm{~S} 6, \mathrm{~S} 7, \mathrm{~S} 9, \mathrm{~S} 17, \mathrm{~S} 18, \mathrm{~S} 19$ & 12.147 & 29.407 & 0.3063 & 1.654 \\
\hline & 0.8 & 0 & $\mathrm{~S} 5, \mathrm{~S} 6, \mathrm{~S} 7, \mathrm{~S} 9, \mathrm{~S} 18, \mathrm{~S} 19, \mathrm{~S} 20$ & 11.171 & 27.558 & 0.3190 & 1.573 \\
\hline & & 1 & $\mathrm{~S} 5, \mathrm{~S} 6, \mathrm{~S} 7, \mathrm{~S} 9, \mathrm{~S} 17, \mathrm{~S} 18, \mathrm{~S} 19$ & 9.29 & 17.99 & 0.2407 & 1.5842 \\
\hline & 0.7 & 0 & $\mathrm{~S} 5, \mathrm{~S} 6, \mathrm{~S} 7, \mathrm{~S} 9, \mathrm{~S} 18, \mathrm{~S} 19, \mathrm{~S} 20$ & 8.187 & 15.343 & 0.2390 & 1.546 \\
\hline & & 1 & $\mathrm{~S} 5, \mathrm{~S} 6, \mathrm{~S} 7, \mathrm{~S} 9, \mathrm{~S} 17, \mathrm{~S} 18, \mathrm{~S} 19$ & 6.913 & 8.571 & 0.1774 & 1.549 \\
\hline & 0.6 & 0 & $\mathrm{~S} 5, \mathrm{~S} 6, \mathrm{~S} 7, \mathrm{~S} 9, \mathrm{~S} 18, \mathrm{~S} 19, \mathrm{~S} 20$ & 5.734 & 5.367 & 0.1604 & 1.544 \\
\hline & & 1 & $\mathrm{~S} 5, \mathrm{~S} 6, \mathrm{~S} 7, \mathrm{~S} 9, \mathrm{~S} 17, \mathrm{~S} 18, \mathrm{~S} 19$ & 4.889 & 0.480 & 0.1130 & 1.556 \\
\hline
\end{tabular}

modified 30 node meshed distribution system integrated with DG, and multiple computations carried out for different time-varying load levels. The optimality of the radial networks obtained through the application of Kruskal's maximal spanning tree algorithm for different loading levels was verified by comparing the power loss and L-index values with those obtained from (randomly selected) manually configured radial networks. The performance of the proposed technique was further compared with another similar graph theory technique known as Edmond's algorithm, and it was found that the proposed technique performed better for DG integrated networks. The results of the study suggest that the proper application of Kruskal's maximal spanning tree algorithm in distributed generation integrated electrical networks can help power system researchers and operators quickly identify and obtain the most optimal radial network that can be reconfigured from the meshed network.

Funding This research did not receive any specific grant from funding agencies in the public, commercial, or not-for-profit sectors.

\section{Declarations}

Conflict of interest The authors declare that they have no conflict of interest.

Open Access This article is licensed under a Creative Commons Attribution 4.0 International License, which permits use, sharing, adaptation, distribution and reproduction in any medium or format, as long as you give appropriate credit to the original author(s) and the source, provide a link to the Creative Commons licence, and indicate if changes were made. The images or other third party material in this article are included in the article's Creative Commons licence, unless indicated otherwise in a credit line to the material. If material is not included in the article's Creative Commons licence and your intended use is not permitted by statutory regulation or exceeds the permitted use, you will need to obtain permission directly from the copyright holder. To view a copy of this licence, visit http://creativecommons. org/licenses/by/4.0/.

\section{Appendix}

See Fig 9 is modeled as per Table 14 and Tables 11, 12, 13, 14,15 and 16 .

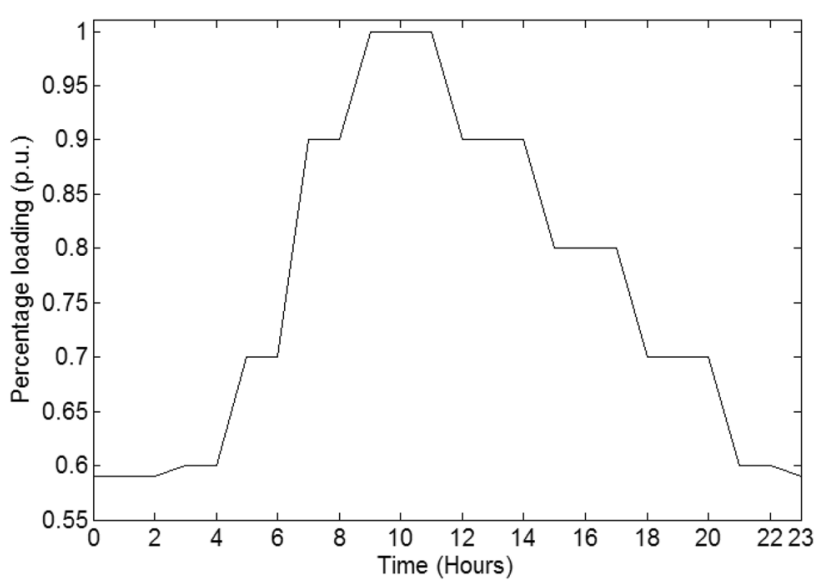

Fig. 9 Percentage loading versus time plot corresponding to Table 14

Table 11 The 3-node test system line data [37]

\begin{tabular}{lllll}
\hline Start node & End node & $R$ (p.u.) & $X$ (p.u.) & $\begin{array}{l}\text { Section- } \\
\text { alizing } \\
\text { switch }\end{array}$ \\
\hline 1 & 2 & 0.02 & 0.04 & S1 \\
1 & 3 & 0.01 & 0.03 & S2 \\
2 & 3 & 0.0125 & 0.025 & S3 \\
\hline
\end{tabular}




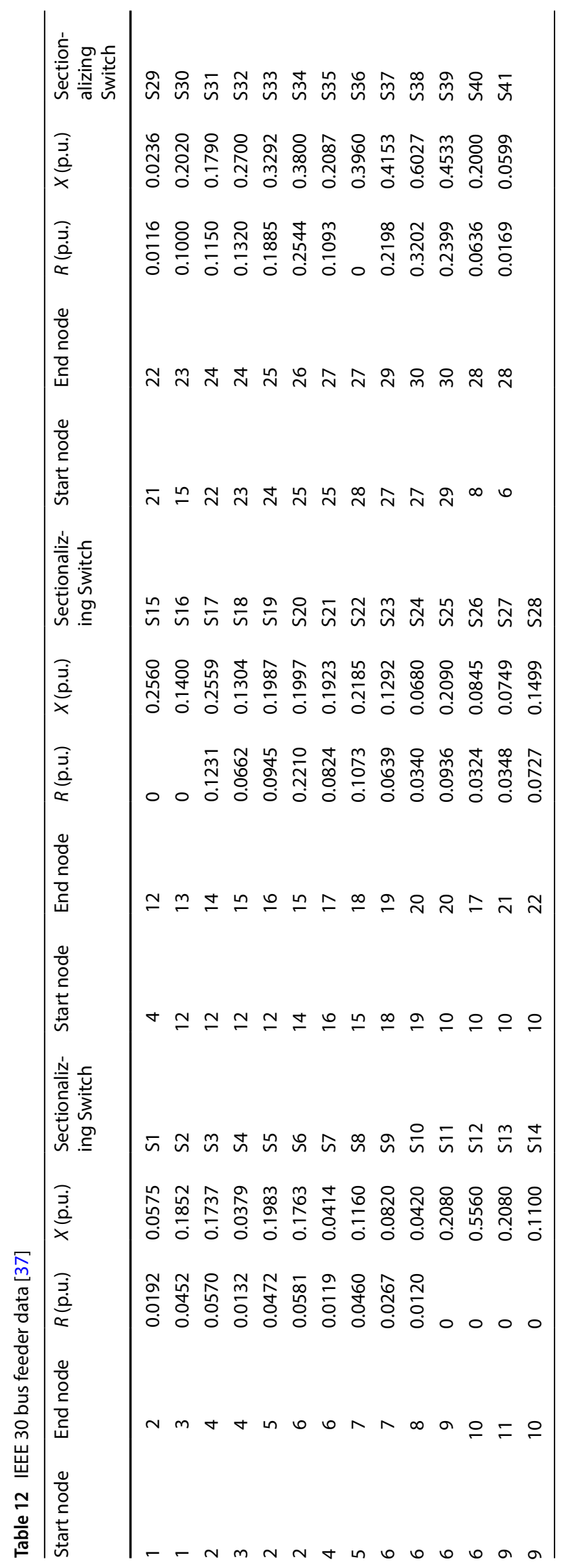


Table 13 IEEE 30 bus busdata [37]

\begin{tabular}{|c|c|c|c|c|c|c|c|c|c|c|}
\hline \multirow[t]{2}{*}{ Bus no } & \multirow[t]{2}{*}{ Bus types* } & \multicolumn{2}{|l|}{ Voltage } & \multicolumn{2}{|l|}{ Load } & \multicolumn{5}{|c|}{ Generator } \\
\hline & & Magnitude & Angle & MW & MVAR & MW & MVAR & Qmin & Qmax & Static MVAR \\
\hline 1 & Slack bus & 1.06 & 0.0 & 0.0 & 0.0 & 0.0 & 0.0 & 0.0 & 0.0 & 0.0 \\
\hline 2 & PV & 1.043 & 0.0 & 21.7 & 12.7 & 40.0 & 0.0 & -40.0 & 50.0 & 0.0 \\
\hline 3 & $\mathrm{PQ}$ & 1.000 & 0.0 & 2.4 & 1.2 & 0.0 & 0.0 & 0.0 & 0.0 & 0.0 \\
\hline 4 & $\mathrm{PQ}$ & 1.060 & 0.0 & 7.6 & 1.6 & 0.0 & 0.0 & 0.0 & 0.0 & 0.0 \\
\hline 5 & PV & 1.010 & 0.0 & 94.2 & 19.0 & 0.0 & 0.0 & -40 & 40.0 & 0.0 \\
\hline 6 & $\mathrm{PQ}$ & 1.000 & 0.0 & 0.0 & 0.0 & 0.0 & 0.0 & 0.0 & 0.0 & 0.0 \\
\hline 7 & $\mathrm{PQ}$ & 1.000 & 0.0 & 22.8 & 10.9 & 0.0 & 0.0 & 0.0 & 0.0 & 0.0 \\
\hline 8 & PV & 1.010 & 0.0 & 30.0 & 30.0 & 0.0 & 0.0 & -10 & 40.0 & 0.0 \\
\hline 9 & $\mathrm{PQ}$ & 1.000 & 0.0 & 0.0 & 0.0 & 0.0 & 0.0 & 0.0 & 0.0 & 0.0 \\
\hline 10 & $\mathrm{PQ}$ & 1.000 & 0.0 & 5.8 & 2.0 & 0.0 & 0.0 & 0.0 & 0.0 & 0.0 \\
\hline 11 & PV & 1.082 & 0.0 & 0.0 & 0.0 & 0.0 & 0.0 & -6 & 24.0 & 19 \\
\hline 12 & $\mathrm{PQ}$ & 1.000 & 0.0 & 11.2 & 7.5 & 0.0 & 0.0 & 0.0 & 0.0 & 0.0 \\
\hline 13 & PV & 1.071 & 0.0 & 0.0 & 0.0 & 0.0 & 0.0 & -6 & 24.0 & 0.0 \\
\hline 14 & $P Q$ & 1.000 & 0.0 & 6.2 & 1.6 & 0.0 & 0.0 & 0.0 & 0.0 & 0.0 \\
\hline 15 & $P Q$ & 1.000 & 0.0 & 8.2 & 2.5 & 0.0 & 0.0 & 0.0 & 0.0 & 0.0 \\
\hline 16 & $\mathrm{PQ}$ & 1.000 & 0.0 & 3.5 & 1.8 & 0.0 & 0.0 & 0.0 & 0.0 & 0.0 \\
\hline 17 & $P Q$ & 1.000 & 0.0 & 9.0 & 5.8 & 0.0 & 0.0 & 0.0 & 0.0 & 0.0 \\
\hline 18 & $\mathrm{PQ}$ & 1.000 & 0.0 & 3.2 & 0.9 & 0.0 & 0.0 & 0.0 & 0.0 & 0.0 \\
\hline 19 & $P Q$ & 1.000 & 0.0 & 9.5 & 3.4 & 0.0 & 0.0 & 0.0 & 0.0 & 0.0 \\
\hline 20 & $\mathrm{PQ}$ & 1.000 & 0.0 & 2.2 & 0.7 & 0.0 & 0.0 & 0.0 & 0.0 & 0.0 \\
\hline 21 & $\mathrm{PQ}$ & 1.000 & 0.0 & 17.5 & 11.2 & 0.0 & 0.0 & 0.0 & 0.0 & 0.0 \\
\hline 22 & $P Q$ & 1.000 & 0.0 & 0.0 & 0.0 & 0.0 & 0.0 & 0.0 & 0.0 & 0.0 \\
\hline 23 & $P Q$ & 1.000 & 0.0 & 3.2 & 1.6 & 0.0 & 0.0 & 0.0 & 0.0 & 0.0 \\
\hline 24 & $P Q$ & 1.000 & 0.0 & 8.7 & 6.7 & 0.0 & 0.0 & 0.0 & 0.0 & 0.0 \\
\hline 25 & $\mathrm{PQ}$ & 1.000 & 0.0 & 0.0 & 0.0 & 0.0 & 0.0 & 0.0 & 0.0 & 4.3 \\
\hline 26 & $P Q$ & 1.000 & 0.0 & 3.5 & 2.3 & 0.0 & 0.0 & 0.0 & 0.0 & 0.0 \\
\hline 27 & $\mathrm{PQ}$ & 1.000 & 0.0 & 0.0 & 0.0 & 0.0 & 0.0 & 0.0 & 0.0 & 0.0 \\
\hline 28 & $P Q$ & 1.000 & 0.0 & 0.0 & 0.0 & 0.0 & 0.0 & 0.0 & 0.0 & 0.0 \\
\hline 29 & $\mathrm{PQ}$ & 1.000 & 0.0 & 2.4 & 0.9 & 0.0 & 0.0 & 0.0 & 0.0 & 0.0 \\
\hline 30 & $P Q$ & 1.000 & 0.0 & 10.6 & 1.9 & 0.0 & 0.0 & 0.0 & 0.0 & 0.0 \\
\hline
\end{tabular}

*slack bus = ref bus, PV bus= gen bus, $P Q$ bus= load bus 
Table 14 Time-varying loading considered

\begin{tabular}{llll}
\hline Time (hours) & Load level (p.u.) & Time (hours) & Load level $($ p.u. $)$ \\
\hline $0-2$ & $0.59(59 \%$ of base load $)$ & $12-14$ & $0.9(90 \%$ of base load $)$ \\
$3-4$ & $0.6(60 \%$ of base load $)$ & $15-17$ & $0.8(80 \%$ of base load $)$ \\
$5-6$ & $0.7(70 \%$ of base load $)$ & $18-20$ & $0.7(70 \%$ of base load $)$ \\
$7-8$ & $0.9(90 \%$ of base load $)$ & $21-22$ & $0.6(60 \%$ of base load $)$ \\
$9-11$ & 1.0 (base load $\left.^{*}\right)$ & $23-24$ & $0.59(59 \%$ of base load $)$ \\
\hline
\end{tabular}

*The total maximum load or full load of the system was considered as base-load
Table 15 Data of doubly-fed induction machine (DFIG) wind turbine [38]

\begin{tabular}{lcllll}
\hline Power rating $S_{n}(\mathrm{MVA})$ & 60.0 & Magnetization reactance $X_{m}$ (p.u.) & 3.00 & Number of poles $p$ & 4 \\
\hline Voltage rating $V_{n}(\mathrm{kV})$ & 0.48 & Initial constant $H_{m}(\mathrm{kWs} / \mathrm{kVA})$ & 3.00 & Number of Blades $n_{b}$ & 3 \\
Frequency rating $f_{n}(\mathrm{~Hz})$ & 60.0 & Pitch control gain $K_{p}($ p.u. $)$ & 10 & Gear box ratio $\eta_{\mathrm{GB}}$ & $1 / 89$ \\
Stator resistance $R_{s}$ (p.u.) & 0.01 & Pitch control time constant $T_{p}(\mathrm{~s})$ & 3 & $P_{\max }($ p.u. $)$ & 1.0 \\
Stator reactance $X_{s}$ (p.u.) & 0.10 Voltage control gain $K_{v}$ (p.u.) & 5 & $P_{\min }$ (p.u.) & -1.0 \\
Rotor resistance $R_{r}$ (p.u.) & 0.01 Power control time constant $T_{e}(\mathrm{~s})$ & 0.01 & $Q_{\max }($ p.u. $)$ & 1.2 \\
Rotor reactance $X_{r}$ (p.u.) & 0.08 Rotor radius $R(\mathrm{~m})$ & 75 & $Q_{\min }$ (p.u.) & -0.7 \\
\hline
\end{tabular}

Table 16 The 14-node test system line data [39]

\begin{tabular}{|c|c|c|c|c|}
\hline Start node & End node & $R$ (p.u.) & $X$ (p.u.) & $\begin{array}{l}\text { Section- } \\
\text { alizing } \\
\text { switch }\end{array}$ \\
\hline 1 & 2 & 0.01938 & 0.05917 & S1 \\
\hline 1 & 5 & 0.05403 & 0.22304 & $\mathrm{~S} 2$ \\
\hline 2 & 3 & 0.04699 & 0.19797 & S3 \\
\hline 2 & 4 & 0.05811 & 0.17632 & S4 \\
\hline 2 & 5 & 0.05695 & 0.17388 & S5 \\
\hline 3 & 4 & 0.06701 & 0.17103 & S6 \\
\hline 4 & 5 & 0.01335 & 0.04211 & S7 \\
\hline 4 & 7 & 0 & 0.20912 & S8 \\
\hline 4 & 9 & 0 & 0.55618 & S9 \\
\hline 5 & 6 & 0 & 0.25202 & $\mathrm{~S} 10$ \\
\hline 6 & 11 & 0.09498 & 0.1989 & $\mathrm{~S} 11$ \\
\hline 6 & 12 & 0.12291 & 0.25581 & $\mathrm{~S} 12$ \\
\hline 6 & 13 & 0.06615 & 0.13027 & $\mathrm{~S} 13$ \\
\hline 7 & 8 & 0 & 0.17615 & S14 \\
\hline 7 & 9 & 0 & 0.11001 & $\mathrm{~S} 15$ \\
\hline 9 & 10 & 0.03181 & 0.0845 & $\mathrm{~S} 16$ \\
\hline 9 & 14 & 0.12711 & 0.27038 & $\mathrm{~S} 17$ \\
\hline 10 & 11 & 0.08205 & 0.19207 & $\mathrm{~S} 18$ \\
\hline 12 & 13 & 0.22092 & 0.19988 & S19 \\
\hline 13 & 14 & 0.17093 & 0.34802 & S20 \\
\hline
\end{tabular}

\section{References}

1. Visali N, Sridevi K, Sreenivasulu N (2017) Mitigation of power quality problems in distribution system using D-STATCOM. In: Emerging trends in electrical, communications and information technologies. Springer, Singapore, pp. 433-443. https:// doi.org/10.1007/978-981-10-1540-3_46

2. Ramana G, Ram BS (2011) Power system stability improvement using FACTS with expert systems. Int J Adv Eng Technol 1:395-404

3. Sakthivel S, Mary D (2011) Voltage stability limit improvement incorporating SSSC and SVC under line outage contingency condition by loss minimization. Eur J Sci Res 59:44-54

4. Taylor CW (1994) Power system voltage stability. McGraw-Hill Inc., New York

5. Santos EO, Martins JS (2018) Distribution power network reconfiguration in the smart grid. arXiv preprint arXiv:1806.07913. https://doi.org/10.5281/zenodo.1066442

6. Sarkar D, Goswami S, De A, Chanda CK, Mukhopadhyay K (2011) Improvement of voltage stability margin in a reconfigured radial power network using graph theory. Can J Electr Electron Eng 2:454-462

7. Goswami SK, Basu SK (1992) A new algorithm for the reconfiguration of distribution feeders for loss minimization. IEEE Trans Power Deliv 7:1484-1491. https://doi.org/10.1109/61.141868

8. Sultana B, Mustafa MW, Sultana U, Bhatti AR (2016) Review on reliability improvement and power loss reduction in distribution system via network reconfiguration. Renew Sustain Energy Rev 66:297-310. https://doi.org/10.1016/j.rser.2016.08.011

9. Lei S, Chen C, Song Y, Hou Y (2020) Radiality constraints for resilient reconfiguration of distribution systems: formulation and application to microgrid formation. IEEE Trans Smart Grid. https://doi.org/10.1109/TPWRS.2020.3009534

10. Zhu W, Shi J, Zhi P, Fan L, Lim G (2020) Distributed reconfiguration of a hybrid shipboard power system. IEEE Trans Power Syst. https://doi.org/10.1109/TPWRS.2020.3009534

11. Sarkar D, Konwar P, De A, Goswami S (2020) A graph theory application for fast and efficient search of optimal radialized 
distribution network topology. J King Saud Univ Eng Sci 32:255264. https://doi.org/10.1016/j.jksues.2019.02.003

12. Kashem MA, Ganapathy V, Jasmon GB (2001) On-line network reconfiguration for enhancement of voltage stability in distribution systems using artificial neural networks. Electr Power Compon Syst 29:361-373. https://doi.org/10.1080/1532500015 1125676

13. Rao PR, Sivanagaraju S (2010) Radial distribution network reconfiguration for loss reduction and load balancing using plant growth simulation algorithm. Int J Electr Eng Inform. https:// doi.org/10.15676/ijeei.2010.2.4.2

14. Nguyen TT, Truong AV (2015) Distribution network reconfiguration for power loss minimization and voltage profile improvement using cuckoo search algorithm. Int J Electr Power Energy Syst 68:233-242. https://doi.org/10.1016/j.ijepes.2014.12.075

15. Arun M, Aravindhababu P (2010) Fuzzy based reconfiguration algorithm for voltage stability enhancement of distribution systems. Expert Syst Appl 37:6974-6978. https://doi.org/10.1016/j. eswa.2010.03.022

16. Bernardon DP, Garcia VJ, Ferreira ASQ, Canha LN (2009) Electric distribution network reconfiguration based on a fuzzy multi-criteria decision making algorithm. Electr Power Syst Res 79:1400-1407. https://doi.org/10.1016/j.epsr.2009.04.012

17. Esmaeilian HR, Fadaeinedjad R (2015) Distribution system efficiency improvement using network reconfiguration and capacitor allocation. Int J Electr Power Energy Syst 64:457-468. https:// doi.org/10.1016/j.ijepes.2014.06.051

18. Kashem MA, Ganapathy V, Jasmon GB (2000) Network reconfiguration for enhancement of voltage stability in distribution networks. IEE Proc Gener Transm Distrib 147:171-175. https:// doi.org/10.1049/ip-gtd:20000302

19. Lopez E, Opazo H, Garcia L, Bastard P (2004) Online reconfiguration considering variability demand: applications to real networks. IEEE Trans Power Syst 19:549-553. https://doi.org/10. 1109/TPWRS.2003.821447

20. Razavi SE, Rahimi E, Javadi MS, Nezhad AE, Lotfi M, Shafie-khah M, Catalão JP (2019) Impact of distributed generation on protection and voltage regulation of distribution systems: a review. Renew Sustain Energy Rev 105:157-167. https://doi.org/10. 1016/j.rser.2019.01.050

21. Di Santo KG, Kanashiro E, Di Santo SG, Saidel MA (2015) A review on smart grids and experiences in Brazil. Renew Sustain Energy Rev 52:1072-1082. https://doi.org/10.1016/j.rser.2015.07.182

22. Abapour S, Zare K, Mohammadi-Ivatloo B (2015) Dynamic planning of distributed generation units in active distribution network. IET Gener Transm Distrib 9:1455-1463. https://doi.org/10. 1049/iet-gtd.2014.1143

23. Abdmouleh Z, Gastli A, Ben-Brahim L, Haouari M, Al-Emadi NA (2017) Review of optimization techniques applied for the integration of distributed generation from renewable energy sources. Renew Energy 113:266-280. https://doi.org/10.1016/j. renene.2017.05.087

24. Pesaran MHA, Huy PD, Ramachandaramurthy VK (2017) A review of the optimal allocation of distributed generation: objectives, constraints, methods, and algorithms. Renew Sustain Energy Rev 75:293-312. https://doi.org/10.1016/j.rser.2016.10.071

25. Theo WL, Lim JS, Ho WS, Hashim H, Lee CT (2017) Review of distributed generation (DG) system planning and optimisation techniques: comparison of numerical and mathematical modelling methods. Renew Sustain Energy Rev 67:531-573. https:// doi.org/10.1016/j.rser.2016.09.063

26. Murty VVSN, Kumar A (2014) Mesh distribution system analysis in presence of distributed generation with time varying load model. Int J Electr Power Energy Syst 62:836-854. https://doi. org/10.1016/j.ijepes.2014.05.034

27. Kuang H, Li S, Wu Z (2011) Discussion on advantages and disadvantages of distributed generation connected to the grid. In: 2011 International conference on electrical and control engineering. IEEE. Yichang, China, pp. 170-173 https://doi.org/10. 1109/ICECENG.2011.6057500

28. Rajaram R, Kumar KS, Rajasekar N (2015) Power system reconfiguration in a radial distribution network for reducing losses and to improve voltage profile using modified plant growth simulation algorithm with distributed generation (DG). Energy Rep 1:116-122. https://doi.org/10.1016/j.egyr.2015.03.002

29. Caples D, Boljevic S, Conlon MF (2011) Impact of distributed generation on voltage profile in $38 \mathrm{kV}$ distribution system. In: 2011 8th International conference on the European energy market (EEM). IEEE. Zagreb, Croatia, pp. 532-536). https://doi.org/ 10.1109/EEM.2011.5953069

30. Roy NK, Mahmud MA, Pota HR (2011) Impact of high wind penetration on the voltage profile of distribution systems. In: 2011 North american power symposium. IEEE. Boston. https://doi. org/10.1109/NAPS.2011.6025195

31. Thong VV, Driesen J (2008) Distributed generation and power quality-case study. In: Cap 16 handbook of power quality edited by Angelo Baggini. Wiley, EUA

32. Jasmon GB, Lee LHCC (1993) New contingency ranking technique incorporating a voltage stability criterion. In: IEE Proceedings C (Generation, Transmission and Distribution). IET Digital Library, 140: 87-90. https://doi.org/10.1049/ip-c.1993.0012

33. Pemmaraju S, Skiena S (2003) Kruskal's Algorithm. In: Computational discrete mathematics: combinatorics and graph theory in mathematica. Cambridge University Press, England, pp 336-338

34. Cormen TH, Leiserson CE, Rivest RL, Stein C (2001) Introduction to algorithms, Second Edition. MIT Press and McGraw-Hill,. ISBN 0-262-03293-7. In Section 23.2: The algorithms of Kruskal and Prim, pp 567-574

35. Chu YJ (1965) On the shortest arborescence of a directed graph. Sci Sinica 14:1396-1400

36. Edmonds J (1967) Optimum branchings. J Res Natl Bur Stand B 71:233-240

37. Saadat H (1999) Power system analysis, vol 2. McGraw-Hill, Chennai

38. Muñoz JC, Cañizares CA (2011) Comparative stability analysis of DFIG-based wind farms and conventional synchronous generators. In 2011 IEEE/PES power systems conference and exposition, pp. 1-7. https://doi.org/10.1109/PSCE.2011.5772545

39. Power system test case archive, available at: http://www.ee. washington.edu/research/pstca/

Publisher's Note Springer Nature remains neutral with regard to jurisdictional claims in published maps and institutional affiliations. 